\title{
Grammatical Abilities of Greek-Speaking Children with Autism
}

\author{
Arhonto Terzi \\ Technological Educational Institute of Western Greece at Patras \\ Theodoros Marinis \\ University of Reading \\ Angeliki Kotsopoulou \\ Technological Educational Institute of Western Greece at Patras \\ Konstantinos Francis \\ University of Athens
}

\begin{abstract}
This study investigates pronoun reference and verbs with nonactive morphology in high-functioning Greek-speaking children with Autism Spectrum Disorders (ASD). It is motivated by problems with reflexive pronouns demonstrated by English-speaking children with ASD and the fact that reflexivity is also expressed via nonactive (reflexive) verbs in Greek. Twenty 5- to 8-year-old children with ASD and 20 vocabulary-matched typically developing controls of the same age range completed a sentence-picture matching, an elicitation, and a judgment task. Children with ASD did not differ from controls in interpreting reflexive and strong pronouns but were less accurate in the comprehension of clitics and omitted clitics in their production. The findings render clitics a vulnerable domain for autism in Greek, and potentially for other languages with clitics, and suggest that this could be a consequence of difficulties in the syntax-pragmatics or the syntax-phonology interface. The two groups did not differ in the comprehension of nonactive morphology but were less accurate in passive than reflexive verbs. We argue that this is likely to stem from the linguistic representation associated with each type of verb, rather than their input frequency.
\end{abstract}

Correspondence should be sent to Arhonto Terzi, Technological Educational Institute of Western Greece at Patras, Speech and Language Therapy, Meg. Alexandrou 1, Patras, 26334 Greece. E-mail: aterzi@ teipat.gr 


\section{INTRODUCTION}

Autism Spectrum Disorder (ASD) is a developmental disorder characterized by atypical reciprocal social interaction, atypical communication, and restricted repetitive and stereotyped patterns of behavior, interests, and activities (ICD-10, World Health Organisation 1993). Research on the language abilities of children with ASD has mostly focused on pragmatics and prosody-a consequence of the fact that, cross-linguistically, autism implicates impairment in discourse abilities and pragmatics (Tager-Flusberg 1999) and atypical expressive prosody (McCann \& Peppé, 2003). In contrast, grammatical aspects of children with ASD have received much less attention, and when they do, they often address the relation and input of elements of grammar to communication and social interaction (Colle et al. 2008; Hobson, Lee \& Hobson 2010). As a consequence, important aspects of the morphosyntactic abilities of the individuals studied have often remained undetected. Moreover, the few existing studies that investigate grammatical abilities of children with ASD have focused on English-speaking children. Therefore, it is unclear whether the findings are specific to English or whether they can be generalized cross-linguistically. The present study addresses the grammatical abilities of children with ASD by investigating two areas of grammar of high-functioning Greek-speaking children, enabling us to bring in a crosslinguistic dimension to the study of language abilities in autism and to start profiling the language abilities of Greek-speaking children with ASD in particular. The study focuses on two areas of grammar that have preoccupied extensively the literature on typical language development cross-linguistically: comprehension/binding of pronouns and passive sentences.

\subsection{Morphosyntactic Abilities in Children with Autism}

Earlier studies on the acquisition of morphosyntax in children with ASD often concluded that they do not differ from typically developing (TD) children (Tager-Flusberg et al. 1990). However, a common characteristic of most early studies is that they have not taken into close account the significant heterogeneity among children with autism in terms of their verbal and nonverbal abilities. As a result, important aspects of their linguistic profile, and particular difficulties in morphosyntax, often remained undetected (Bartolucci \& Albers 1974; Bartolucci, Pierce \& Streiner 1980).

More recently, studies on the language abilities of individuals with ASD have identified subgroups of children on the basis of standardized assessments measuring verbal and nonverbal abilities (e.g., Kjelgaard \& Tager-Flusberg 2001; Roberts, Rice \& Tager-Flusberg 2004). These have shown that some children with ASD have normal language skills on all standardized tests, whereas others perform below their chronological age, and, to some extent, similarly to children with Specific Language Impairment (SLI). Roberts, Rice \& Tager-Flusberg (2004) in particular compared the performance of participants with ASD (aged 5 to 15) to children with SLI on tense marking, an area of grammar that has been claimed to be a clinical marker for SLI in English. This study included three groups of participants with ASD, divided on the basis of their scores on the Peabody Picture Vocabulary Test (PPVT) (Dunn \& Dunn 1997): (1) Group 1 with PPVT scores within the normal range (85 or higher), (2) Group 2 with PPVT scores between 1 and 2 standard deviations from the mean (70-84), and (3) Group 3 with PPVT scores below 2 or more standard deviations from the mean. In terms of nonverbal IQ, all participants from Group 
1 performed within the normal range, whereas this was the case for fewer than half of the children in Group 2, and only in 4 out of the 19 participants from Group 3. In the production of tense morphology, Group 3 was less accurate than the other two groups in third person singular $-s$, regular and irregular past tense. Comparison between participants with ASD and children with SLI showed that the scores of Group 3 on third person singular $-s$ and regular past tense were worse than those of children with SLI in the same age range. Moreover, their error pattern differed from that of children with SLI: Low-functioning participants with ASD tended to use echolalic responses or to perseverate on previous responses, and they used semantically inappropriate, off-topic responses. The use of echolalia and perseverance was interpreted to reflect difficulties in understanding the instructions or the nature of the task, whereas semantically inappropriate responses were interpreted to reflect deficits in pragmatics. However, the language-impaired participants with ASD had low nonverbal IQ, whereas the nonverbal IQ of the children with SLI was within norms. Therefore, it is unclear whether or not the difference between the groups was due to differences in the children's nonverbal abilities. Finally, it is unclear whether the group of ASD participants with normal language and nonverbal abilities showed age-appropriate production of tense marking because this study did not include a TD control group.

A more-recent study that included a TD control group was the study by Eigsti \& Bennetto (2009). The authors used a grammaticality judgment task to test a wide range of morphosyntactic phenomena in high-functioning English-speaking children with autism, aged 9 to 17, and TD controls matched on age, verbal, and nonverbal abilities. The results showed that children with autism had lower sensitivity to morphosyntactic violations than TD controls only in two phenomena, omission of third person singular $-s$ and progressive aspect $-i n g$. This finding is different from what we know about children with SLI (Leonard 1998), and the researchers suggest that it is general learnability properties, rather than particular grammatical structures, that cause the differences between the two populations.

A TD control group was included also in a recent study by Riches et al. (2010) that used a sentence-repetition task to compare the morphosyntactic abilities of adolescents with ASD and language impairment (ALI) to the profile of adolescents with SLI and TD age-matched controls. The three groups had nonverbal abilities within norms, but the adolescents with ALI and the adolescents with SLI had verbal abilities of $-1.5 S D$ or below. The sentence-repetition task consisted of subject and object relative clauses, structures that are difficult for children with SLI (e.g., Novogrodsky \& Friedmann 2006). Adjectives were used in two different positions within the relative clauses to increase the complexity of the sentences. The results showed that adolescents with ALI and SLI were less accurate than controls in repeating sentences, and there was no significant difference between the two groups of language-impaired children in their overall accuracy. However, there were some important differences between the two language-impaired groups: Adolescents with SLI were affected more than adolescents with ALI from the complexity of the sentences, and adolescents with SLI had higher error rates on object relative clauses than adolescents with ALI. This finding is in contrast to Roberts et al. (2004), who showed better performance in children with SLI compared to language-impaired participants with ASD. However, this difference could relate to nonverbal abilities. Most language-impaired participants with ASD in Roberts, Rice \& Tager-Flusberg (2004) had below-average nonverbal IQ, whereas the children with ASD in Riches et al. (2010) had nonverbal IQ within norms.

Another study that investigated morphosyntactic abilities of children with ASD is the one by Perovic, Modyanova, \& Wexler (2013), which focused on the comprehension of pronouns 
and reflexives in children and adolescents. Pronouns and reflexives have been argued to be affected in children with SLI (Lely \& Stollwerck 1997), although this issue is currently under debate (see Novogrodsky \& Friedmann 2010). The participants with autism had low language and nonverbal abilities and were compared to two groups of younger TD children, one matched on language abilities and a second one matched on nonverbal abilities. This study used a twochoice picture-selection task adapted from Wexler \& Chien (1985). Results showed that the participants with ASD performed similarly to two groups of younger controls on the comprehension of pronouns, but their performance was disproportionally affected on the comprehension of reflexives. Perovic, Modyanova \& Wexler (2013) argued that this behavior reflects impairment in the grammatical knowledge of individuals with ASD instead of a general language delay or cognitive deficits. However, it is unclear whether or not participants with ASD with normal nonverbal and verbal abilities demonstrate a similar deficit in the comprehension of reflexives.

To conclude, it is unclear whether or not the difficulties in morphosyntax that children with ASD show are attested only in children with low verbal and nonverbal abilities and whether these are phenomena that are also vulnerable in children with SLI. Finally, most studies on the morphosyntactic abilities of children with ASD have focused on English-speaking children. Therefore, it is unclear whether or not the difficulties attested in previous studies hold crosslinguistically. The pattern that Perovic, Modyanova \& Wexler (2013) discovered is exceptional, and, if found in other languages, it could be established as an area of grammar particularly vulnerable in ASD populations.

The current study addresses the acquisition of two areas of grammar that have been found problematic either in children with ASD or in children with SLI, or are especially delayed in TD language. Moreover, the two areas form a natural continuum in the grammar of Greek, as will be explained in subsequent sections. To address the issue of whether or not specific grammatical abilities of children with ASD relate to verbal and nonverbal abilities, we followed very strict inclusion and exclusion criteria and recruited only ASD children within a narrow age range and with high verbal and nonverbal abilities. This was done to ensure that difficulties in particular areas of grammar are not related to intellectual disabilities or the atypical social interaction that characterize this disorder. Finally, by focusing on Greek-speaking children, we are able to address whether or not previous findings on difficulties in the grammar of children with ASD hold cross-linguistically, hence, can be considered to characterize the linguistic profile of ASD populations.

\subsection{Acquisition of Pronouns and Nonactive Morphology by Greek TD and Language-Impaired Children}

The current study focuses on two domains of grammar, the reference of pronouns and nonactive verbal morphology. Choosing these two domains for investigation was motivated by research on the acquisition of morphosyntax of English-speaking children with ASD, as reported in the previous section, on the acquisition of these two domains by Greek TD children and children with language impairment, and, finally, on properties of the Greek grammar that render these two domains a natural continuum to study, in a manner to be explained later in this subsection. In what follows we will introduce the properties of Greek that are relevant for the study and will 
report previous findings on the acquisition of these and related areas of grammar by Greek TD children and children with language impairment.

\subsubsection{Pronouns}

Greek, along with many Romance, Germanic (although not English), and Slavic languages, distinguishes personal object pronouns into strong (or full) pronouns, as in (1), and clitic pronouns (or clitics), as in (2).

(1) O Kostas ide afton the Kostas saw.3s him.full pronoun

(2) O Kostas ton ide. the Kostas him.clitic pronoun saw.3s 'Kostas saw him.'

Besides the obvious difference that strong pronouns carry lexical stress, whereas clitic pronouns are unstressed and cliticize onto the verb, the two types of pronouns also differ in many other important respects, namely, syntactically, semantically, phonologically, and pragmatically (see Mavrogiorgos 2011 for a recent thorough review). Nevertheless, they also share similarities. Firstly, both strong and clitic pronouns inflect for gender, number, and case. Moreover, they both are considered to be subject to Principle B of binding theory, that is, they cannot refer to an antecedent within the same sentence. As a result, afton 'him' in (1) and ton 'him' in (2) cannot refer to Kostas.

Research on the acquisition of binding principles in Greek has demonstrated that TD children master Principle B early and do not make errors in the comprehension of either strong or clitic pronouns (Varlokosta 2000). This is in contrast to what seems to be the case with the strong pronouns of many other languages, e.g., English (Wexler \& Chien 1985; Chien \& Wexler 1990, among many others, although see Conroy et al. 2009 for criticisms), including languages that have both strong and clitic pronouns, e.g., Italian and Spanish. In the latter type of languages, children are known to delay in acquiring the interpretation of strong pronouns but not of clitics (McKee 1992; Avrutin \& Wexler 1992; Baauw, Escobar \& Philip 1997).

Varlokosta (2008) has attributed Greek-speaking children's early mastery of pronoun reference to the fact that Greek strong pronouns are also demonstratives, as is demonstrated in (3).

(3) Ida afton ton anthropo

saw.1s this the man

'I saw this man.'

Demonstratives, by contrast to strong pronouns, may also refer to nonhuman entities, as pointed out by Cardinaletti \& Starke (1999), and Greek is not an exception, as Varlokosta (2008) points out. Hence, one of the properties of (the demonstratives that also serve as) strong pronouns in Greek is that they cannot establish accidental coreference with their antecedents, by contrast to English strong pronouns. As a result, sentences such as (4) are not grammatical in Greek with him referring to Bill. 
(4) I know what Mary, Sue and Bill have in common. Mary likes him, Sue likes him, and Bill likes him too. ${ }^{1}$

Nevertheless, despite the differences between Greek strong pronouns and those of other languages, and the differences between strong pronouns and clitic pronouns in Greek, Greek personal pronouns, both strong and clitics, cannot refer to an antecedent within the same clause, and this is what is important for our current purposes. Moreover, as already mentioned, TD Greek-speaking children do well on them from early on.

Research on the acquisition of pronouns by Greek children with SLI has shown that they have no difficulties producing strong pronouns, but they show a considerable omission of clitics (Tsimpli \& Stavrakaki 1999; Mastropavlou 2006; Smith 2009; Stavrakaki \& Lely 2010), results that do not agree with those of Manika, Varlokosta \& Wexler (2011), however. Disagreement also emerges when it comes to the comprehension of strong pronouns and clitics. Varlokosta (2002) reports that the eight children with SLI she studied via a truth value-judgement task are divided into two groups: those (three children) whose behavior matches that of TD children (hence, they do not demonstrate delay of Principle B), and those (five) who differ from TD children and demonstrate delay of Principle B, but on both strong pronouns and clitics. On the other hand, using a picture-matching task, Stavrakaki \& Lely (2010) found that children with SLI (nine in total) have intact comprehension of strong pronouns, but they make errors in the comprehension of clitics. What is interesting about their errors, for reasons to which we will return later in the article, is that the predominant pattern involves thematic role reversal, with the second-highest number of errors consisting of interpreting clitics as reflexives. Finally, Chondrogianni, Marinis \& Edwards (2010) found that Greek children with SLI are not sensitive to clitic omission when they process sentences in real time. Given the various difficulties of Greek children with SLI with clitics, clitics were proposed to be clinical markers for SLI in Greek (Tsimpli \& Stavrakaki 1999).

Proceeding to reflexive pronouns, these are complex forms in Greek, as seen in (5), and are inflected for number and case.

(5) O Kostas agapai ton eafto tu. the Kostas love.3s the self his 'Kostas loves himself.'

Reflexive pronouns are subject to Principle A; hence, they have to have an antecedent within the same clause. Therefore, Kostas does not love anyone else but himself in sentence (5), just like in its English counterpart in the translation. Nevertheless, as first pointed out by Iatridou (1988), the morphosyntactic properties of Greek reflexives are substantially different from those of other languages, including English. Descriptively, Greek reflexives are like nouns, in the sense that they are preceded by a determiner and are followed by a possessive pronoun (cf., ton adelfo tu $=$ the brother his = 'his brother'). More recently, Anagnostopoulou \& Everaert (1999) revisited Greek reflexives in an attempt to place them within the classificatory system of Reinhart \& Reuland (1993) and concluded that, unlike the reflexives that had been described by Reinhart \& Reuland, Greek reflexives are fully specified for phi-features; hence, they instantiate a new category of

\footnotetext{
${ }^{1}$ A reviewer comments that him can be interpreted as coreferential with Bill in the last conjunct of (4) only if it is replaced by Bill in its first occurance, unlike what is argued to be the case in the related literature (see Conroy et al. 2009 for a recent survey). It seems to us that even then, coreference is impossible in Greek.
} 
reflexives. Anagnostopoulou \& Everaert also proposed that a consequence of these particular morphosyntactic properties of Greek reflexives is that they incorporate into the predicate they reflexivize. $^{2}$

Language acquisition research has shown that binding of reflexive pronouns is acquired early by TD children cross-linguistically, a pattern that also holds for Greek-speaking children (Varlokosta 2000, 2002). As for children with SLI, the study by Stavrakaki \& Lely (2010) found that the nine Greek-speaking children they studied performed at ceiling on reflexives.

Recall at this point that the current study was motivated to a large extent by the findings of Perovic, Modyanova \& Wexler (2013), according to which English-speaking children with ASD encounter problems precisely with binding of reflexive pronouns, an area of grammar that is not problematic in typical development, as just mentioned. An immediate consequence of such a finding therefore is that one wants to know how widespread this behavior may be, since, if found to hold cross-linguistically, it would characterize the linguistic profile of a specific atypical population. When it comes to Greek, however, except for being expressed via the reflexive pronouns, reflexivity can also be expressed via special verbal morphology. This is referred to as nonactive morphology, creating the necessity to investigate how children with ASD behave on this manifestation of reflexivity. Finally, since the morphology of reflexive verbs is shared by passive verbs in the language, and given that the latter is an area that has attracted a lot of attention in typical language acquisition cross-linguistically, the next question that arises is how individuals with ASD perform on passives, and how this behavior compares to their behavior on reflexive verbs with which they share the same morphology. These are the reasons that make us focus on these two domains of grammar in ASD, namely, pronoun binding and nonactive morphology. In what follows we proceed with presenting the core properties of the verbs that appear with nonactive morphology, and, in particular, of passive and reflexive verbs.

\subsubsection{Nonactive Verbal Morphology}

Just as is the case with a number of other languages, Greek employs the same morphology to mark passive and reflexive constructions, but also anticausatives, reciprocals, and middles (Alexiadou \& Anagnostopoulou 2004, and see Zombolou 2004 for an exhaustive list of readings associated with the same morphology). In Greek, this is (nonactive) inflectional morphology on the verb, as the following two examples demonstrate. See also Zombolou (2004) and Alexiadou, Anagnostopoulou \& Schäfer (2006) for detailed discussion of passives versus anticausatives and Papangeli (2004) for reflexive verbs in Greek and cross-linguistically.

(6) I Maria sproxnete. the Mary push.3s.non-act

'Mary is pushed.' (passive)

(7) I Maria htenizete.

the Mary comb.3s.non-act

'Mary combed herself.' (reflexive)

\footnotetext{
${ }^{2}$ See Spathas (2010) for additional differences between Greek and English reflexive pronouns.
} 
A test that has been employed to distinguish passive from reflexive readings of verbs with nonactive morphology is the use of the prepositional phrase apo monos/moni tu/tis 'on his/her own,' according to which modification is possible in (7), but not in (6) (Alexiadou \& Anagnostopoulou 2004, Papangeli 2004). Based on this criterion, we will call verbs as in (6) passive verbs and those as in (7) reflexive verbs. Importantly, sentences with reflexive verbs can also have a passive interpretation, given the appropriate context (see Tsimpli 2006). Thus, based on the context, Mary can be combing herself or can be combed by her hairdresser in (7).

Acquisition of nonactive verbal morphology has been studied to a good extent in Greek, and a conclusion that has emerged is that (verbal) passives are not mastered early by TD children, as assessed in a variety of tasks (comprehension: Terzi \& Wexler 2002 and Driva \& Terzi 2008, and production: Zombolou et al. 2010). Ages tested were 3;08-5;10, 3;06-6;06, and $2 ; 07-4 ; 03$ respectively, and the delay was attributed to maturation of A-chains in the first two studies and presence of Voice $\mathrm{P}$ in the latter study, which, furthermore, compared passives with anticausatives.

Tsimpli (2006) has also studied the acquisition of verbs with nonactive morphology by TD Greek-speaking children. Most relevant for our research is the preferential picture-selection task on verbs that can have either a reflexive or a passive interpretation. Tsimpli found that 3- to 6-yearold children prefer the reflexive interpretation by far for verbs that adults associate with reflexive interpretation exclusively. Nevertheless, a number of them chose the passive interpretation even at younger ages (while some chose the active/transitive). The actual percentages are $18 \%$ and $20 \%$ for the passive interpretation for 3- to 4 -year-olds and 5- to 6-year-olds respectively, and $20 \%$ and $10 \%$ for the active interpretation for the two age groups (see her Table 5). On the basis of the passive choice that children made for verbs with nonactive morphology that adults only interpret as reflexives, she concluded that passive interpretation of nonactive verbs is available to TD Greek-speaking children of these ages.

Verbs with nonactive morphology and reflexive interpretation are interesting for the current study for two reasons. Firstly, because they constitute an additional manner of expressing reflexivity in Greek besides reflexive pronouns; hence, they provide an additional domain with which to compare our findings from reflexive pronouns, the area that was found problematic among English-speaking populations with ASD. Secondly, because reflexive verbs share the same morphology with passives, and the latter have been argued to develop late in Greek, and crosslinguistically (Borer \& Wexler 1987, Wexler 2004), although not without some debate (Demuth 1989, see also Tsimpli 2006; Fotiadou \& Tsimpli 2010). Finally, to our knowledge, there are no studies on the acquisition of nonactive morphology by non-TD Greek-speaking children.

\section{METHODOLOGY}

\subsection{Participants}

The present study included twenty 5- to 8-year-old children with autism (mean age 6;08) and 20 typically developing children of similar chronological age $(t(38)=0.429, p>0.1)$. Strict inclusion and exclusion criteria were used. The ASD children were clinically diagnosed with an Autism Spectrum Disorder using DSM-IV-TR criteria (American Psychiatric Association 1994), 
and the diagnosis was corroborated with the use of Autism Diagnostic Observation ScheduleADOS (Lord et al. 2000). All children had nonverbal abilities of 80 and above on the Raven's Coloured Progressive matrices. ${ }^{3}$ ASD and TD children were individually matched $(+/-5$ points) on the raw score of a vocabulary test (see procedures). The ASD children were recruited from intervention centers primarily in Athens, specialized for children with ASD. The TD children were recruited from mainstream schools in Patras. Finally, an adult control group of 20 students, from the various Engineering Departments of the Technological Educational Institute of Patras, completed the experimental task as well. They were 18- to 23-year-old native speakers of Greek whose parents were also native speakers of Greek.

\subsection{Tasks}

\subsubsection{Baseline Tasks}

A battery of baseline tasks was used to ascertain the children's verbal and nonverbal abilities. The Raven's Coloured Progressive matrices (Raven 1998) assessed the children's nonverbal abilities, and the production of morphosyntax subtest of the Diagnostic Test of Verbal Intelligence (DVIQ, Stavrakaki \& Tsimpli, 2000) was used to assess children's morphosyntactic abilities. In addition, the children completed a receptive vocabulary task and a task assessing pragmatics. The vocabulary task was a picture-pointing task with a format based on PPVT (Dunn \& Dunn 1997), and the pragmatics test was based on the Diagnostic Evaluation of Language Variation (DELV, Seymour et al. 2005) pragmatics subtest.

Table 1 shows the children's performance on the baseline tasks. The two groups did not differ in their nonverbal abilities $(t(38)=-1.436, p>0.1)$ and in their vocabulary $(t(38)=0.49, p=$ $0.1)$. The children with ASD had a slightly lower performance in the production of morphosyntax, but this difference did not reach significance $(t(38)=1.809, p=0.078)$. Finally, the children with ASD had a significantly lower score on the pragmatics test compared to the TD children $(t(38)=$ $2.674, p=0.01)$.

\subsubsection{Experimental Task}

A picture-selection task was designed to assess the interpretation of pronouns and nonactive morphology. The task included six conditions testing (1) strong pronouns, (2) clitic pronouns, (3) reflexive pronouns, (4) passive verbs (with passive interpretation), (5) reflexive verbs (with reflexive interpretation), and (6) reflexive verbs with passive interpretation.

Six sentences were created for each of the above conditions; hence, the task consisted of a total of 36 sentences. Each sentence was presented together with three pictures: One was the target picture and the other two foils. The sentences were prerecorded by two female native speakers of

\footnotetext{
${ }^{3}$ Three children with ASD initially recruited for the study were not included in this article because their Raven's score was below 80 . The phrase “. . . 5- to 8-year-old children . . ." is misleading, since only 1 of the 20 children of each group was over 8 years old. Mean ages are a more accurate manner to characterize the age of the participants. In any case, the actual ages of the ASD children were 5;06, 5;08, 5;09, 6;01, 6;02, 6;06, 6;08 (3), 6;09, 6;10, 6;11, 7;01, 7;02 (2), 7;03, $7 ; 07$ (2), 7;11, 8;11, and the ages of TD children were: 5;06, 5;08, 5;09, 6;01, 6;02, 6;06, 6;08 (3), 6;09, 6;10, 6;11, 7;01, $7 ; 02$ (2), 7;03, 7;07 (2), 7;11, and 8;00.
} 
TABLE 1

Children's Characteristics

\begin{tabular}{|c|c|c|c|c|c|}
\hline Group & Age in months & Nonverbal IQ* & $D V I Q^{\dagger}$ & Vocabulary $^{\dagger}$ & Pragmatics $^{\dagger}$ \\
\hline \multicolumn{6}{|c|}{ ASD children } \\
\hline Mean & 79.8 & 103.5 & 19.9 & 102.3 & 16.6 \\
\hline$S D$ & 10.4 & 13.1 & 2.9 & 22.7 & 3.6 \\
\hline Range & $61-107$ & $80-135$ & $12-24$ & $57-143$ & $5-22$ \\
\hline \multicolumn{6}{|c|}{ TD children } \\
\hline Mean & 81.1 & 98 & 21.3 & 102.7 & 19.5 \\
\hline$S D$ & 8.7 & 11.1 & 1.6 & 22.8 & 3.1 \\
\hline Range & $66-96$ & $80-120$ & $19-24$ & $62-141$ & $12-24$ \\
\hline
\end{tabular}

*Nonverbal IQ: standard score.

${ }^{\dagger}$ DVIQ, Vocabulary, Pragmatics: raw score.

Greek using normal speed and natural intonation in a noise-isolated booth. Adobe Audition was used to edit the recorded sentences. The pictures were designed by a professional designer, and care was taken to avoid biases due to the size and prominence of the figures in them. Sentences were administered in pseudorandom order. Moreover, position of the three pictures in each slide was random for the entire group of sentences. We describe the material for each condition and present representative sets of sentences and pictures in detail. The complete set of sentences used in the experimental task is provided in the Appendix.

\subsubsection{Material}

2.2.2.1.1. Condition 1: Strong pronouns. Six actional verbs were used to create the sentences involving strong pronouns (pleno 'wash,' luzo 'shampoo,' dino 'dress,' skupizo 'wipe,' skepazo 'cover,' haidevo 'caress'). The subject of each sentence was a proper name or a kinship term, and the strong pronoun was always the object of the sentence, as shown in (8).

(8) I Maria pleni aftin.

the Mary wash.3s she.acc.full pronoun

'Mary is washing her.'

To avoid gender cues, both subject and object had the same gender, masculine or feminine (half and half). In example (8), the strong pronoun corresponded to the aunt. Therefore, the target picture showed Maria washing the aunt, as shown in Figure 1. The second picture depicted the same persons with their thematic-roles reversed, i.e., the aunt was washing Maria (theta-role reversal in Table 2). The third picture depicted the subject of the sentence doing a reflexive action with the verb of the sentence (reflexive interpretation in Table 2). To make all pictures similar in terms of the number of participants in each picture, the pictures with the reflexive action included the other person, in this example the aunt, watching nearby.

2.2.2.1.2. Condition 2: Clitic pronouns. The same six verbs used with strong pronouns were also used with clitic pronouns. As in the previous condition, the subject of each sentence was a proper name or a kinship term, but this time the object was a clitic pronoun, as shown in (9), and different persons were associated with each verb. 

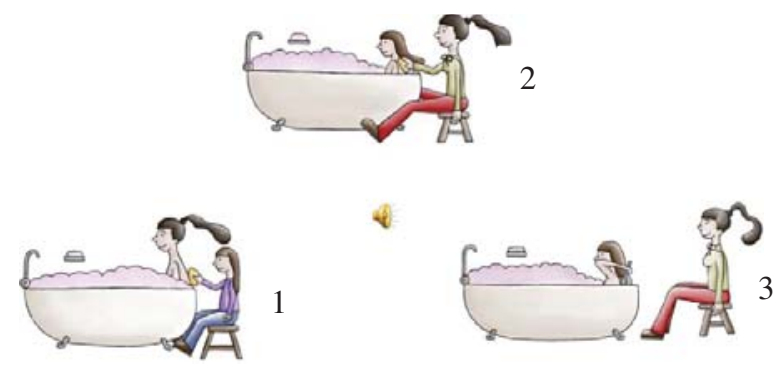

FIGURE 1 Strong pronouns. 1 target picture; 2 theta-role reversal;

$3=$ reflexive interpretation.

TABLE 2

Error Analysis: Pronoun Reference

\begin{tabular}{lccc}
\hline & $A S D$ & $T D$ & Adult controls \\
\hline Strong Pronouns & & & \\
$\quad$ Reflexive interpretation & $6 / 6$ & $8 / 8$ & $14 / 14$ \\
$\quad$ Theta-role reversal & $0 / 6$ & $0 / 8$ & $0 / 14$ \\
Clitics & & & $1 / 1$ \\
$\quad$ Reflexive interpretation & $4 / 14$ & $0 / 1$ & $0 / 1$ \\
$\quad$ Theta-role reversal & $10 / 14$ & $1 / 1$ & $0 / 0$ \\
Reflexive Pronouns & & & $0 / 0$ \\
$\quad$ Pronoun interpretation & $3 / 3$ & $1 / 1$ & $0 / 1$ \\
$\quad$ Reflexive interpretation, different agent & $0 / 3$ & & \\
\hline
\end{tabular}

(9) I mama tin pleni.

the mom she.acc.clitic wash.3s

'Mom is washing her.'

The target picture for this sentence showed mom washing Kate, as shown in Figure 2. As in the condition with strong pronouns, the second picture showed the same persons with the thematic roles reversed (theta-role reversal), and the third picture depicted the subject of the sentence, i.e., mom, doing a reflexive action, i.e., washing herself, while Kate was watching nearby (reflexive interpretation).

2.2.2.1.3. Condition 3: Reflexive pronouns. Three of the verbs used in Conditions 1 and 2 were also used in Condition 3 (skupizo 'wipe,' skepazo 'cover,' haidevo 'caress') together with three other verbs that are considered felicitous with a reflexive pronoun as their object (zografizo 'paint,' agaliazo 'hug,' kitazo 'look at'). ${ }^{4}$ The three verbs of the previous two conditions that were

\footnotetext{
${ }^{4} \mathrm{~A}$ reviewer comments that the same verbs should have been used in all three conditions, and moreover, they should be verbs that do not express reflexivity with nonactive morphology. The first suggestion is fulfilled to a large extent, since we used the same verbs in all three conditions, except for three verbs in the reflexive pronouns condition, which were new. As to the second suggestion, it cannot be considered, because it was our intention to compare reflexivity as expressed with reflexive pronouns and reflexivity as expressed via verbal morphology, precisely because of the problems encountered with English reflexive pronouns. After considering the results, it emerges that the findings are not challenged
} 


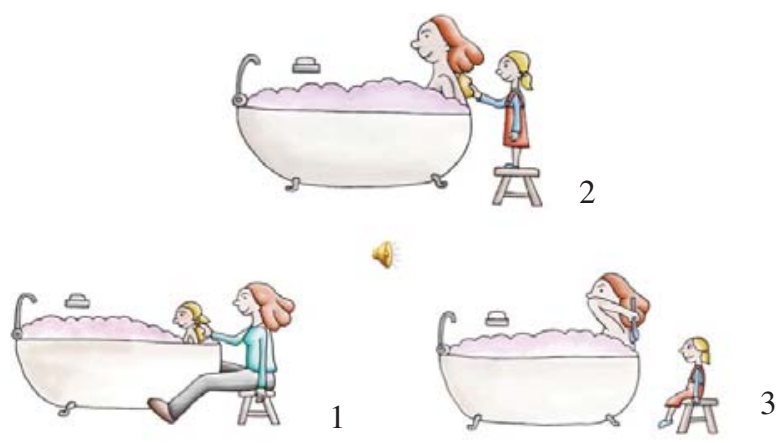

FIGURE 2 Clitics. $1=$ target picture; 2 theta-role reversal; $3=$ reflexive interpretation.

not used in Condition 3 express reflexivity more naturally with nonactive morphology rather than with active morphology and a reflexive pronoun as their object (two of them were body-care verbs). As previously, the subject of each sentence was a proper name or a kinship term, but this time the object was a reflexive pronoun, as shown in (10), and different persons were associated with each verb than in the first two conditions.

(10) O Giorgos skepazi ton eafto tu. the George cover.3s the self his

'George is covering himself.'

The target picture for this sentence showed Giorgos covering himself and a second person (the grandfather) standing nearby, as shown in Figure 3. The second picture depicted the person corresponding to the subject of the sentence (Giorgos) doing the action associated with the verb of the sentence (cover) upon another person (the grandfather). This is the pronoun interpretation in Table 2. The third picture depicted the same reflexive action as in the target picture, but the agent is the other person and not the subject of the sentence, i.e., the grandfather covering himself while Giorgos is standing nearby (reflexive interpretation-different agent in Table 2). As we will see later, the pictures of this condition are of the same type as in Condition 5, which tests verbs with nonactive morphology and reflexive interpretation.

\subsubsection{Verbs with nonactive morphology}

2.2.2.2.1. Condition 4: Passive verbs with passive interpretation. This condition tested verbs with nonactive morphology and passive interpretation, namely, the verbs we considered as passive according to the criterion in section 1.3.2. Six new actional verbs were used (kinigao 'chase,' klotsao 'kick,' tsimbao 'pinch,' sprohno 'push,' taizo 'feed,' filao 'kiss') with nonactive morphology and proper names or kinship terms as subjects. The sentences were short passives, i.e., they consisted of the subject and the verb, but no by-phrase, (11).

by any of the comments. Binding of reflexive pronouns is almost at ceiling, while the conditions testing binding of strong pronouns and clitics, which could potentially be an issue, since performance of ASD and TD children on clitics is different, do indeed include the same verbs. 

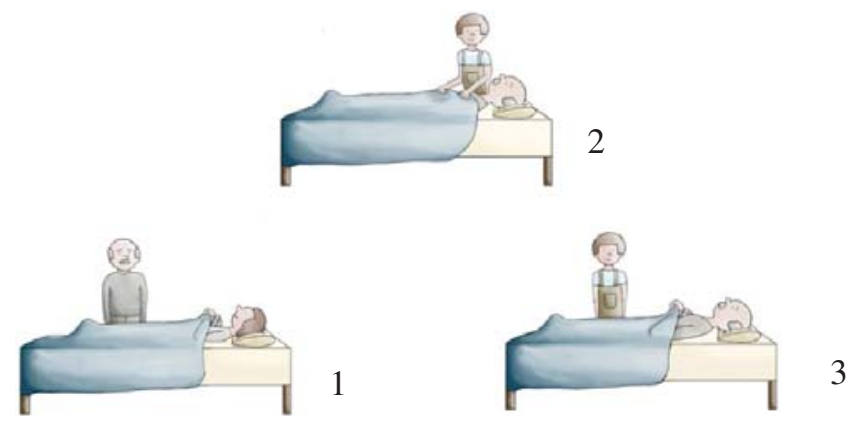

FIGURE 3 Reflexive pronouns. $1=$ target picture; 2 pronoun interpretation; 3 = reflexive, different agent.

(11) O papus taizete.

the grandpa feed.3s.non-act

'Grandpa is being fed.'

The target picture showed the subject in the patient role and someone else in the agent role, i.e., in the example the grandfather being fed by the grandmother, as shown in Figure 4. The second picture showed the same action with reversed theta-roles, namely, the grandfather feeding the grandmother (theta-role reversal, same in Table 3), while the third picture showed the grandfather feeding another person (theta-role reversal, different in Table 3).

2.2.2.2.2. Condition 5: Reflexive verbs with reflexive interpretation. This condition tested what we consider reflexive verbs (see section 1.3.2) on their reflexive interpretation. They were the very same verbs of Conditions 1 and 2; hence, three of them were the same verbs as in Condition 3, while the other three verbs were different. This is so because not all verbs with nonactive morphology and reflexive interpretation can also appear with reflexive pronounsthese are the verbs of body care, for instance, which sound very unnatural with an active verb and

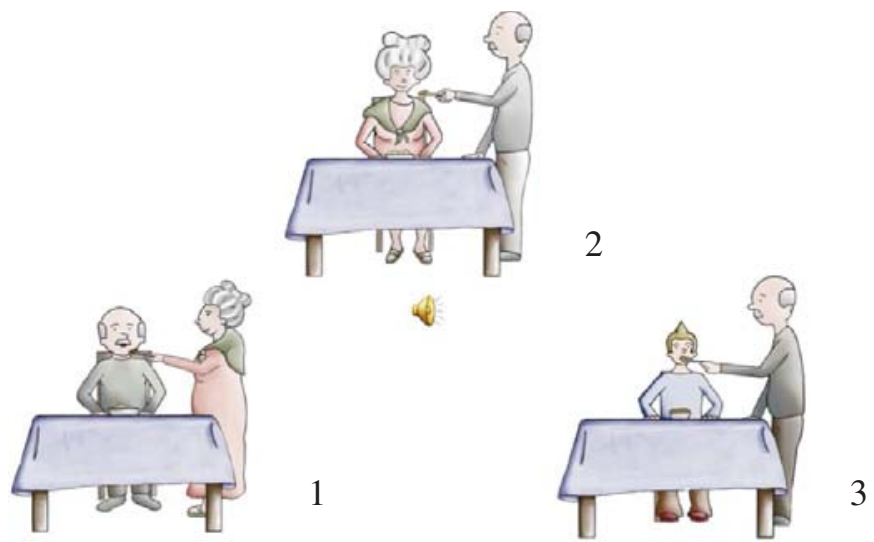

FIGURE 4 Passive verbs with passive interpretation. $1=$ target picture;

2 theta-role reversal; $3=$ theta-role reversal, different. 
TABLE 3

Error Analysis: Nonactive Morphology

\begin{tabular}{lccc}
\hline & $A S D$ & $T D$ & Adult controls \\
\hline Passive verbs passive interpretation & & & $0 / 0$ \\
$\quad$ Theta-role reversal, same & $21 / 40$ & $22 / 36$ & $0 / 0$ \\
$\quad$ Theta-role reversal, different & $19 / 40$ & $14 / 36$ & $0 / 0$ \\
Reflexive verbs reflexive interpretation & & $1 / 1$ & $0 / 0$ \\
$\quad$ Transitive interpretation & $3 / 4$ & $0 / 1$ & $0 / 0$ \\
$\quad$ Reflexive interpretation, different & $1 / 4$ & $0 / 6$ & $0 / 0$ \\
Reflexive verbs passive interpretation & & $6 / 6$ & \\
$\quad$ Theta-role reversal, same & $4 / 8$ & $4 / 8$ & \\
$\quad$ Theta-role reversal, different & & & \\
\hline
\end{tabular}

a reflexive pronoun as its object. The following is an example of a verb that qualifies as reflexive by the criterion in 1.3.2, but is not a body-care verb.

(12) O Petros skepazete.

the Petros cover.3s.non-act

'Petros is covering himself.'

The target picture for this sentence depicted the subject (Petros) covering himself, while another person, the grandfather, was standing by, as shown in Figure 5. The second picture showed the subject performing a transitive action, hence, covering someone else (the grandfather). This is the transitive interpretation in 3. The third picture showed the grandfather covering himself while Petros was standing nearby (reflexive interpretation, different in Table 3 ). The sets of pictures in this condition were the same as in Condition 3. By using the same set of pictures (although with different persons associated with each verb than in Condition 3), we wanted to find out whether the manner of expressing reflexivity, i.e., via active verbs followed by a reflexive pronoun or via nonactive reflexive verbs made any difference.

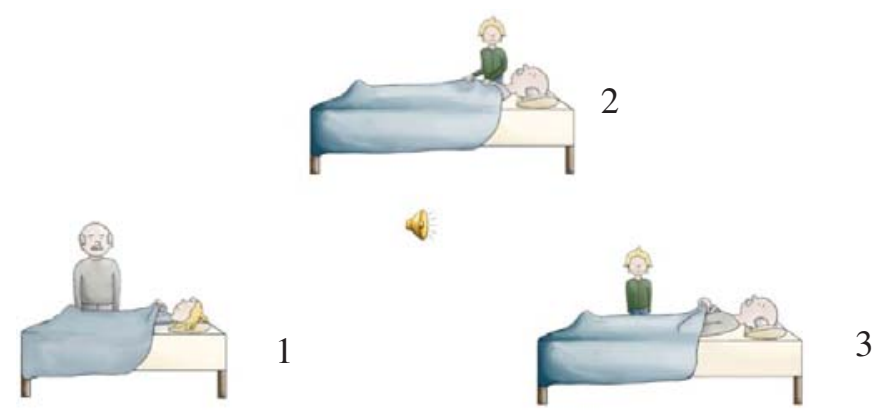

FIGURE 5 Reflexive verbs with reflexive interpretation. $1=$ target picture; 2 transitive interpretation; $3=$ reflexive interpretation, different. 


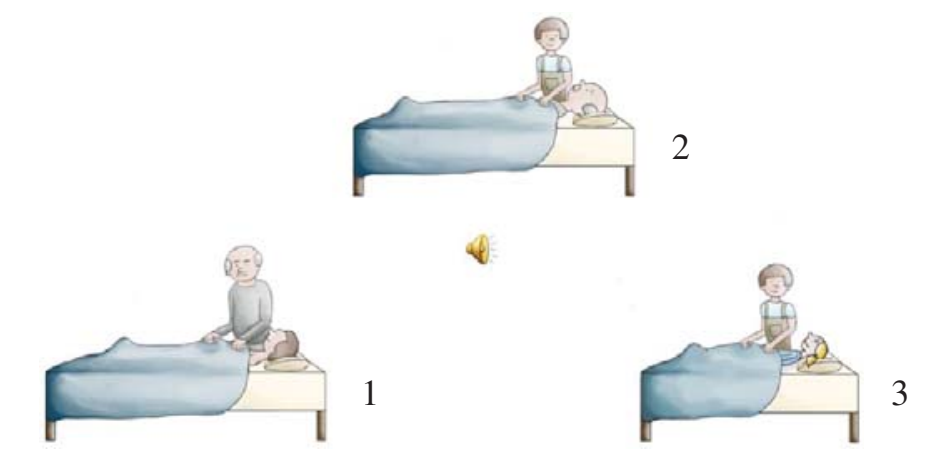

FIGURE 6 Reflexive verbs with passive interpretation. $1=$ target picture;

2 theta-role reversal; $3=$ theta-role reversal, different.

2.2.2.2.3. Condition 6: Reflexive verbs with passive interpretation. This condition tested performance on the same verbs as in Condition 5, namely on verbs that are naturally interpreted as reflexive verbs when they appear with nonactive morphology. However, this time we did not want to investigate the children's grasp of this interpretation, as this was tested in the previous condition. Instead, given that nonactive morphology is also shared by passive verbs, and that reflexive verbs can also have a passive interpretation under appropriate pragmatic conditions, we wanted to see whether the same reflexive verbs fared any better than passive verbs under conditions that allowed them to only have a passive interpretation. Hence, in addition to testing reflexive verbs on reflexive interpretation, in this condition we tested them on their passive interpretation, as in the following example.

(13) O Giorgos skepazete. the George cover.3s.non-act

'George is being covered.'

The target picture for (13) showed George being covered by the grandfather in Figure 6. The second picture showed the theta-roles reversed, namely, George covering the grandfather (thetarole reversal, same in Table 3), while the third picture showed George covering someone else, i.e., Kate (theta-role reversal, different in Table 3). Note that we did not give any picture that would prompt a reflexive interpretation in this condition, since our purpose was not to obtain preferential readings between reflexive and passive interpretation of nonactive verbal morphology (see Tsimpli 2006 for the latter). Instead, we wanted to find out how different the children's performance would be when the verbs used could accept a theme subject in an alternative structure. In addition, we were interested in TD children's performance on this particular condition, as it has not been tested before. Given the findings of previous studies, we were predicting that TD children of these ages would not perform very well at passives. However, the question was whether they would interpret this particular type of passives differently. 


\subsection{Procedures}

All children completed the baseline tasks first, in one 45-minute session. In the next session, they completed the experimental task. The experimental task was presented on a laptop using PowerPoint, with children sitting in front of the laptop. In each trial, they first saw a set of three pictures, then they listened to one sentence, and finally they had to choose one picture from the set. Before administering the experimental task, children were shown a picture with all the persons appearing in the various sentences/pictures of the task and were introduced to each of them by their name, i.e., mom, dad, grandma, grandpa, Petros, Maria, etc. The name of each person was written underneath it in this family picture, and the picture remained next to the children during the experiment. This was not to benefit the younger children, but for the experimenter to remember which names to repeat each time a new slide was shown. The experimenter introduced each person with a name in order to ensure that the children could identify them in every single slide, even when they were entirely transparent, as in the case of the grandmother and the grandfather. Two practice trials were used with all children to familiarize them with the task. ${ }^{5}$ Adult controls were given the experimental task in one session, in the same manner as children.

\section{RESULTS}

\subsection{Pronouns}

Table 4 shows the participants' accuracy in the comprehension of strong pronouns, clitics, and reflexive pronouns.

To investigate differences between the three groups and the three pronoun types, we conducted an Analysis of Variance (ANOVA) with Group as a between-subjects factor (ASD, TD, adult controls), and Pronoun Type as a within-subjects factor (full pronouns, clitics, reflexives). This showed a significant interaction between Group and Pronoun Type $(F(3.6,114)=5.08, p=$ $\left.0.001, \eta^{2}=0.151\right)$, reflecting differences in the comprehension of some of the pronouns by the groups. One-way ANOVAs showed no significant differences among the three pronouns in the groups of children, but the adult controls were less accurate on full pronouns than on clitics $(p=0.006)$ and reflexives $(p=0.001)$. There were no significant differences among the three groups on full pronouns and reflexives. However, in the comprehension of clitics, children with ASD were significantly less accurate than TD children and adult controls (both comparisons: $p=0.005) .{ }^{6}$ As for the unexpectedly low performance of adult controls on strong pronouns, see section 6.1.2 for discussion.

\footnotetext{
${ }^{5} \mathrm{~A}$ reviewer expressed doubts as to whether children could remember the names of the persons. Our experience was that they remembered them extremely accurately, and, moreover, even from their first occurrence. This was also true for the control group of the college students we tested; nevertheless, we routinely repeated the names in every single slide. It should also be pointed out that if children could not remember the names, this would presumably affect all conditions/sentences, contrary to fact.

${ }^{6}$ The accuracy of two children with ASD in the comprehension of clitics was at 50\%, which is 2 standard deviations below the mean of the group (88.3\%). Therefore, they could be classified as outliers. To investigate whether the significant difference between the children with ASD and the two control groups was caused by these two children, we excluded their data and reran the same analyses. These analyses showed also a significant difference between the children with
} 
TABLE 4

Participants' Accuracy on Clitics, Strong Pronouns, and Reflexives (\%)

\begin{tabular}{|c|c|c|c|}
\hline Group & Strong pronouns & Clitics & Reflexives \\
\hline \multicolumn{4}{|c|}{ ASD children } \\
\hline Mean & 94.9 & 88.3 & 97.5 \\
\hline$S D$ & 8 & 17.2 & 6.2 \\
\hline Range & $83-100$ & $50-100$ & $83-00$ \\
\hline \multicolumn{4}{|c|}{ TD children } \\
\hline Mean & 93.3 & 99.2 & 99.2 \\
\hline$S D$ & 13.7 & 3.8 & 3.8 \\
\hline Range & $50-100$ & $83-100$ & $83-100$ \\
\hline \multicolumn{4}{|c|}{ Adult controls } \\
\hline Mean & 88.3 & 99.2 & 100 \\
\hline$S D$ & 12.2 & 3.8 & 0 \\
\hline Range & $67-100$ & $83-100$ & 100 \\
\hline
\end{tabular}

\subsubsection{Individual Variation}

To investigate individual variation within the three groups, we plotted the proportion of accurate responses for each child in each group, as shown in the plots in Figure 7. The plots show that in strong pronouns the TD and ASD children made a small number of errors (five TD children made one to three errors; six children with ASD made one error) whereas 11 adults made one to two errors, resulting in the difference between adults and children in strong pronouns. In reflexives, an even smaller number of children (one TD child; three children with ASD) made one error, and the adults performed at ceiling. This is why there is no difference on reflexives among the three groups. In clitics, the TD children and the adult controls were at ceiling, with only one child and one adult making one error, whereas eight children with ASD made one to three errors.

\subsubsection{Error Analysis}

To uncover the error pattern in the groups, we analyzed the responses of the children in terms of the choices they made when their response was inaccurate. Table 2 shows the number of inaccurate responses per condition for each group separately.

In all three conditions, a very small number of errors involved participants interpreting the subject of the sentence as the agent of the action depicted in the picture (ASD group: strong pronouns $=6$, clitics $=4$, reflexives $=3$; TD children: strong pronouns $=8$, clitics $=0$, reflexives $=1$; adult controls: strong pronouns $=14$, clitics $=1$, reflexives $=0$ ). This gave rise to interpretation of strong pronouns as reflexives and vice versa. However, in the condition with clitic pronouns, the majority of errors in children with ASD (10 out of 14) involved theta-role reversal (see section 2.2.2.1.1, Condition 1, for definition of theta-role reversal).

ASD and the two control groups (both comparisons: $p=0.021$ ), indicating that the difference on clitics was not caused by these two children. 

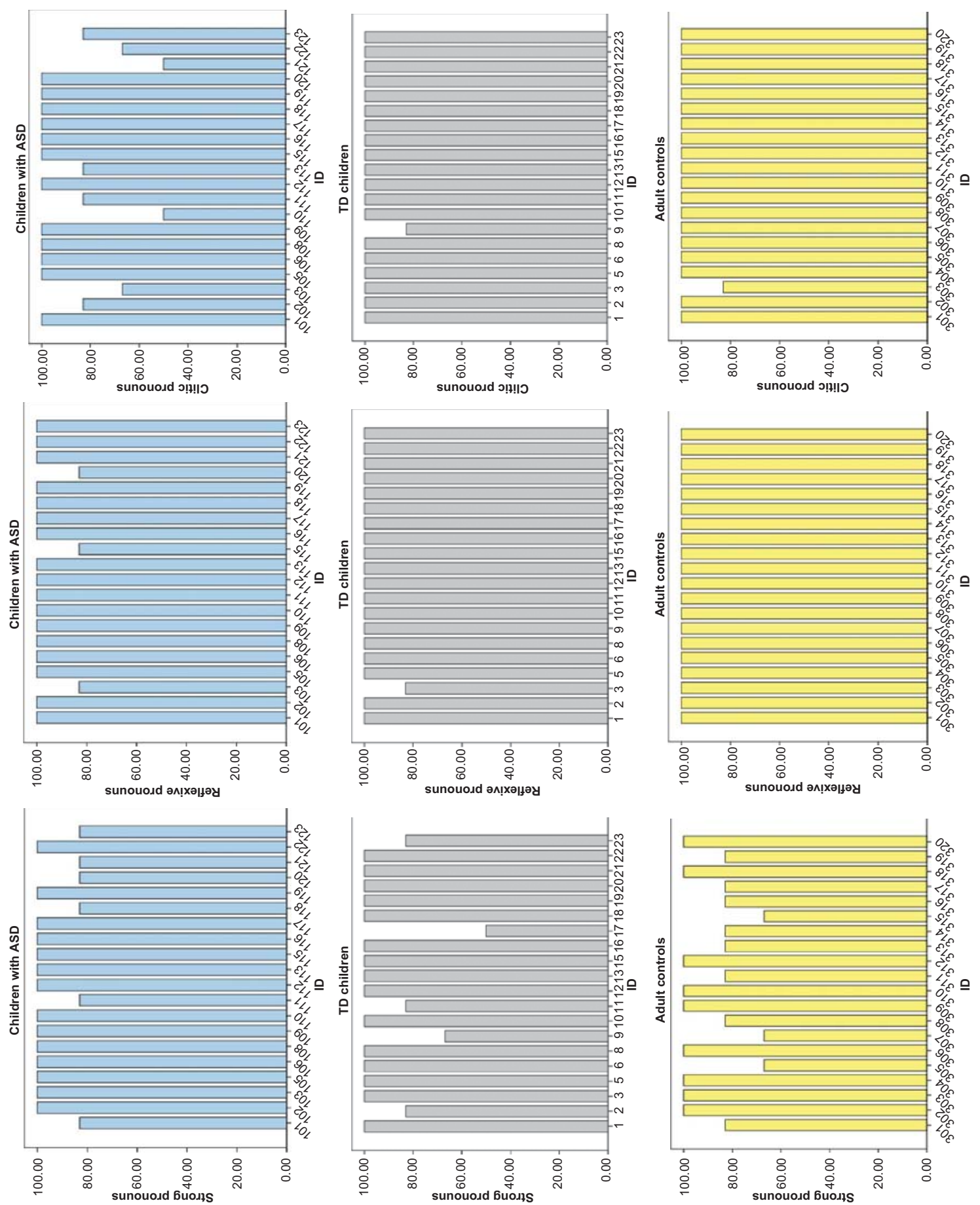

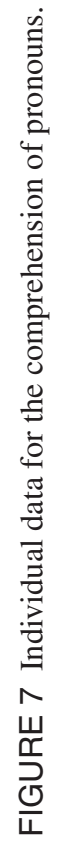




\subsection{Verbs with Nonactive Morphology}

Table 5 shows the participants' accuracy in the comprehension of verbs with nonactive morphology.

An ANOVA with Group as a between-subjects factor (ASD, TD, adult controls) and Verb Type as a within-subjects factor (passive-passive, reflexive-reflexive, reflexive-passive) was conducted to investigate differences between the groups and among the three verb types. This showed a significant main effect of group $\left(F(2,57)=17.88, p<0.001, \eta^{2}=0.386\right)$, a significant main effect of verb type $\left(F(1.7,96.7)=55.66, p<0.001, \eta^{2}=0.494\right)$ and a significant interaction between group and verb type $\left(F(3.4,96.7)=13.95, p<0.001, \eta^{2}=0.329\right)$. One-way ANOVAs showed that both groups of children were significantly less accurate in passive verbs with passive interpretation than in reflexive verbs with reflexive interpretation and reflexive verbs with passive interpretation (both comparisons $p<0.001$ ), and there was no difference between reflexive verbs with reflexive interpretation and reflexive verbs with passive interpretation. There were no significant differences among the three groups in reflexive verbs with reflexive interpretation and reflexive verbs with passive interpretation, but both groups of children were significantly less accurate than adult controls in passive verbs with passive interpretation (both comparisons: $p<$ $0.001)$.

\subsubsection{Individual Variation}

There was no individual variation in the adult group. To investigate individual variation in the two groups of children, we plotted the number of accurate responses for each child in each group, as shown in the plots in Figure 8.

The plots show that almost all children in both groups (TD: 19/20; ASD: 17/20) were at ceiling in reflexive verbs with reflexive interpretation, and the majority of children in both groups

TABLE 5

Participants' Accuracy on Nonactive Morphology (\%)

\begin{tabular}{lccc}
\hline Group & $\begin{array}{c}\text { Passive verbs } \\
\text { (passive interpretation) }\end{array}$ & $\begin{array}{c}\text { Reflexive verbs } \\
\text { (reflexive interpretation) }\end{array}$ & $\begin{array}{c}\text { Reflexive verbs } \\
\text { (passive interpretation) }\end{array}$ \\
\hline ASD children & 66.6 & 96.7 & 93.3 \\
Mean & 22.9 & 8.7 & 16.6 \\
SD & $33-100$ & $67-100$ & $33-100$ \\
Range & 70 & & 94.9 \\
TD children & 20 & 99.2 & 8 \\
Mean & $33-100$ & 3.8 & $83-100$ \\
SD & 100 & $83-100$ & 100 \\
Range & 0 & 100 & 0 \\
Adult controls & 100 & 0 & 100 \\
Mean & & 100 & \\
SD & & & \\
Range & & & \\
\hline
\end{tabular}



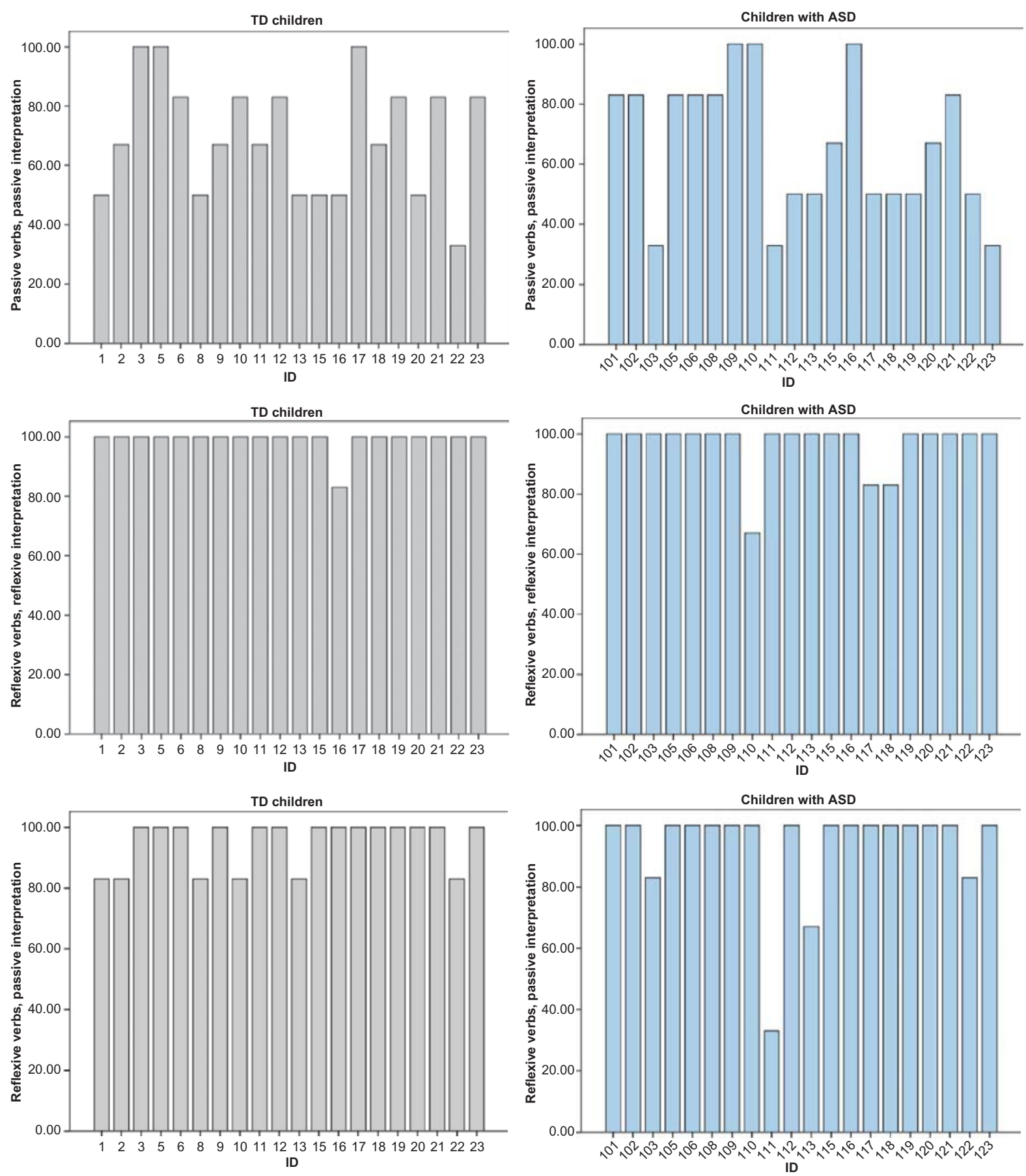

FIGURE 8 Individual data for the comprehension of nonactive morphology.

(TD: 14/20; ASD: 16/20) were at ceiling in reflexive verbs with passive interpretation. In contrast, only 3 out of the 20 children in each group were at ceiling in passive verbs with passive interpretation, and the range in both groups varied from $33 \%$ to $100 \%$. 


\subsubsection{Error Analysis}

To uncover the error pattern in the two groups, we analyzed the responses of the children in terms of the choices they made when their response was inaccurate. Table 3 shows the number of inaccurate responses per condition for each group separately.

There were very few errors in reflexive verbs with reflexive interpretation, and almost all of these errors involved children interpreting the subject of the sentence as the agent of the action depicted in the picture. This gave rise to a transitive interpretation and was the predominant error type attested also in reflexive pronouns. In reflexive verbs with passive interpretation and passive verbs with passive interpretation, the errors involved theta-role reversal, either with the same participants as in the sentence or with the same subject.

\section{INTERIM DISCUSSION}

The aims of this study were to identify the domains of grammar in which high-functioning individuals with ASD may fall behind, to understand the reasons why they differ from typically developing populations, if and when they differ, and to discover the linguistic phenotype of Greek-speaking ASD populations. In this section, we discuss the findings of the study with respect to these issues and relate them to previous findings in the literature.

\subsection{Comparing Groups}

The results from the comprehension of pronouns and nonactive morphology suggest that, except for the performance on pronominal clitics - to which we will return in detail-Greek-speaking high-functioning children with ASD did not behave differently from TD children. We consider this to be an important finding, which indicates that, at least in the domains of grammar that were investigated here, high-functioning Greek-speaking children with ASD do not fall behind TD children.

Why have other studies found problems in ASD children's morphosyntax? We are referring in particular to the studies of Roberts, Rice \& Tager-Flusberg (2004) and Perovic, Modyanova \& Wexler et al. (2013), but also to the findings of Eigsti \& Bennetto (2009), although the latter authors do not interpret their results as revealing problems in grammar. We believe that at least two factors are responsible for the discrepancy between the previous studies and ours: Neither of the first two studies tested exclusively high-functioning ASD children. As a matter of fact, Roberts, Rice \& Tager-Flusberg explicitly distinguish among three language groups of ASD children, defined on the basis of their performance on the PPVT. Of them, only the group with the lowest scores demonstrated problems in grammar, partially similar to children with SLI. On the other hand, Perovic, Modyanova \& Wexler found that the ASD children they studied had low performance on reflexives, a pattern that is not shared by children with SLI, but their sample hardly included any high-functioning children. Since only high-functioning children with ASD were included in the current study, this may explain why their performance was not considerably different from that of the TD controls.

The other factor that may explain why we did not detect serious problems in Greek-speaking ASD children's grammar (except for reference of clitics) is because the domains of grammar on 
which the first and third of these studies focused, and detected problems, have no counterparts in Greek. This is definitely the case with tense/optional infinitives in the study of Roberts, Rice \& Tager-Flusberg, since Greek has no infinitives, but also in the study of Eigsti \& Bennetto (2009), which revealed problems in areas of morphosyntax that do not carry over to Greek (i.e., present progressive). The study of Perovic, Modyanova \& Wexler (2013), which found problems with binding of reflexive pronouns does have a counterpart in Greek, however. Nevertheless, the performance of the Greek-speaking children with ASD that we studied was not found to be impaired in this area of grammar. In what follows immediately, firstly we address this discrepancy between the two studies and languages and proceed subsequently to discussing the other conditions we investigated. $^{7}$

\subsection{Pronoun Reference}

\subsubsection{Reflexive Pronouns: Why Are Greek-Speaking ASD Children Doing Well?}

The first question that arises from our findings is why Greek-speaking children with ASD did not replicate the findings of Perovic, Modyanova \& Wexler (2013) but instead showed high rates of accuracy and performed on a par with TD children on binding of reflexive pronouns. Recall that the aforementioned study constituted an important motivation for the current one, as it seemed to reveal an unprecedented language pattern, which, therefore, had the potential of constituting a linguistic phenotype for autism. At least three factors can be held responsible for the different findings of the two studies.

Firstly, the task in Perovic, Modyanova \& Wexler (2013) may have been substantially more difficult than ours. Most relevant is the fact that the referent of the pronoun in their experiments was embedded in a possessive noun, that is, children were given sentences such as Lisa's mom is pointing to herself to match with pictures. However, if this was the reason for the low scores in reflexives, one may ask why no similar problems were detected with pronouns. Furthermore, the authors state that they had been careful to exclude the possibility that children's problems were due to difficulties with c-command. This is why we will not dwell any longer on this factor as potentially responsible for the low performance of English-speaking children with ASD on reflexives.

Another reason why our study did not discover problems in the area of reflexive pronouns may have to do with the structure of Greek reflexives. Recall from section 1.2 that Greek reflexive pronouns are unlike their English counterparts in various ways. Anagnostopoulou \& Everaert (1999) have proposed that they qualify as +R (and +SELF) — in contrast to the English ones, which are $-\mathrm{R}$ (and +SELF)—by virtue of the fact that they are fully specified for number, gender, and Case. ${ }^{8}$ As a consequence, they do not enter into a chain relation with their antecedents because chains are subject to the Chain Condition of Reinhart \& Reuland (1993), according to which "A maximal A-chain contains exactly one link that is both $+\mathrm{R}$ and Case-marked," and

\footnotetext{
${ }^{7}$ The binding results alone, along with a less-extensive discussion than the current one, are included in Terzi et al. (2012). This work does not include an adult control group, nor the follow-up experiments on clitics that are reported in the following sections of the present article.

${ }^{8}$ In Reinhart \& Reuland (1993) an NP is defined as $+\mathrm{R}$ if and only if it carries full specification for phi-features (number, gender, person).
} 
the head of the chain cannot be -R. A result of this set of differences is, for instance, that nominative anaphors are possible in Greek, but not in English, as demonstrated in (14), which is a grammatical sentence in Greek.

(14) O eaftos tu tu aresi tu Petru. [the self his] him.cl likes the Peter 'Himself pleases/appeals to Peter.'

What follows for Greek reflexives according to this analysis is that they pick up their antecedents not via chain formation, but via incorporation into the associated verb. If the mechanism via which reflexives associate with their antecedents differs in English (A-Chain) versus Greek (incorporation into the verb), and moreover, in this particular manner, it is not surprising to encounter different effects in the process of language acquisition. Alternatively put, it is conceivable that, precisely because Greek reflexive pronouns incorporate into the associated verb, no problems arise for their reference in early Greek. Notice that what Anagnostopoulou \& Everaert (1999) propose renders the structure that contains reflexive pronouns similar to that of reflexive verbs, a view with which they are not preoccupied, and we believe it would take us too far afield to investigate in this article. If, however, one makes this step, one expects similar accuracy levels on reflexive pronouns and reflexive verbs. The picture we obtain for both high-functioning children with ASD and TD children is in full agreement with such an expectation (compare Tables 4 and 5): Children have similar accuracy levels and similar types of errors.

The third factor that may be held responsible for the good performance of the ASD children of our study on reflexives is that they were high-functioning children. The study by Perovic, Modyanova \& Wexler (2013), on the other hand, hardly included any such children. With this particular difference in mind, it occurred to us to take a look at the responses of the three children whose results we did not include in this study because their Raven's score was below 80 and their vocabulary score was also very low. Two of them also had a low score on the DVIQ test (production of morphosyntax). Their correct responses on the six conditions of the experiment were as follows: strong pronouns: $11 / 18$, clitic pronouns: $10 / 18$, reflexive pronouns: $9 / 18$, passive verbs: $5 / 18$, reflexive verbs: $14 / 18$, reflexive verbs with passive interpretation: $13 / 18$. The number of participants and items is obviously too small to draw any firm conclusions. Nevertheless, their responses on reflexive pronouns, particularly of one of the two children's with low DVIQ score, are strikingly low, given how unproblematic binding of reflexives is cross-linguistically, also confirmed by both children groups of our study. Notice, furthermore, that the performance of these three children on reflexive pronouns was worse than on reflexive verbs, by contrast to the two groups of children in our study. These are indications that low-functioning children with autism may have problems with reference of reflexive pronouns even in languages other than English, or, at least, that this possibility should be investigated across the autism spectrum before being abandoned. As to what may be responsible for the low performance of these three children on Greek reflexive pronouns, we believe we should not attempt to speculate before such a pattern is indeed established via a larger group of low-functioning children with ASD. ${ }^{9}$

\footnotetext{
${ }^{9}$ After the article was submitted for publication, one of the reviewers pointed out to us a new study of Greek-speaking children with SLI reporting children with SLI who did worse on binding of reflexive than on binding of clitic pronouns (Varlokosta \& Nerantzini 2012). This is the opposite pattern from the one attested in the study by Stavrakaki \& Lely
} 


\subsubsection{Clitic Pronouns: Why Are Greek-Speaking ASD Children Not Doing Well?}

Although reference of reflexives was found unproblematic for children with ASD, reference of pronominal clitics was not equally unimpaired. This is an area that has not been investigated in English, as the language has no clitics, and is the only area in which children with ASD differed significantly from TD children in our study. We should point out that although they still performed quite well on clitics (88.3\% correct responses), their performance is significantly lower than that of TD children, and also lower than their performance on the other two types of pronouns. Moreover, almost all children were receiving language therapy, and, it is not known what their performance was prior to therapy. In particular, 17 of the 20 children of the ASD group had been offered speech and language therapy for more than 2 years; from the other three children, one had been receiving therapy for a year, the other for three months, while the third one had not received any therapy. Finally, it is important to note that reference/binding of pronominal clitics is mastered early by TD children cross-linguistically, including Greek, as is also demonstrated by the TD children of our group, who performed almost at ceiling (i.e., 99.2\% correct).

As a result, we believe it is legitimate to pose the question why the children with ASD in our study performed worse on reference of pronominal clitics. We can see two reasons that may be responsible for this pattern, neither one of which is directly related to problems with rules of reference (binding principles) per se, but to problems with clitics otherwise. Firstly, as it was reported to us anecdotally by the speech and language pathologist who had worked with the ASD children that participated in this study, children did not seem to produce clitics in their spontaneous speech as often as TD children. Instead, they would produce either the corresponding strong pronoun or the full DP. Less use of clitics is likely to stem from lack of knowledge of the syntactic and pragmatic conditions under which clitics are licensed, which may have consequences for their reference.

A second reason may have to do with specific morphosyntactic problems of ASD children. Notice that the most common error that children made was to choose the picture in which the subject of the sentence was not the agent (as it should be), but the theme/patient. This is the error labelled as theta-role reversal in Table 2. It is interesting that this was the most common error of the Greek-speaking children with SLI in Stavrakaki \& Lely (2010), who attribute it to problems in feature checking associated with complex structures that involve movement (clitics being such structures). Since we did not find that the children with ASD in our study had particular problems with movement (given their performance on passives, which admittedly involves a different type of movement), we decided to look for an alternative explanation. We thought that such an error may arise if children with ASD interpret sentences such as (8), as in (15). The latter is an instance of clitic left dislocation and constitutes a misinterpretation that can easily arise if there are difficulties comprehending the case of the definite article that introduces the subject DP.

(2010) for children with SLI and the findings in the present study for high-functioning children with ASD. This contrast is very likely to be due to the different methodologies used. Varlokosta \& Nerantzini (2012) used a binary picture-selection task that does not include the condition on which the children with SLI in Stavrakaki \& Lely and the ASD children in our study committed the majority of errors on clitics. Therefore, the studies are not directly comparable. If such a pattern is indeed established for children with SLI, it would be interesting to see whether problems with reflexives hold across various types of atypical language and why, as the reviewer suggested. 
(8) I mama tin pleni.

the.nom mom.nom she.cl.acc wash.3s

'Mom is washing her.'

(15) $\mathrm{Ti}$ mama tin pro pleni.

the.acc mom.acc she.cl.acc (he $/$ she) wash.3s

'(He/she) washes mom.'

We decided to explore both ideas in order to find out what was implicated in the low performance of clitic reference in our findings.

\section{FOLLOW-UP STUDIES ON CLITIC PRONOUNS}

Given the lower performance of children with autism on binding of clitic pronouns, we followed up our ideas about the possible causes of their low performance with two experiments: one on the production of clitics and one on case marking. Both experiments were conducted about six months after the first data collection. They were administered within the same day, but not all children could participate, for reasons we explain.

\subsection{Follow-Up Study 1: Production of Clitics}

Difficulties with the reference of clitics could result from children's lack of knowledge of the syntactic and pragmatic conditions under which clitics are licensed in the first place. If this is the case, children with ASD are expected to fall behind in the production of clitics as well. To address the latter issue, we conducted Follow-up Study 1.

\subsubsection{Methodology}

Sixteen out of the 20 ASD children of the initial study participated in this study, along with their 16 age-matched TD controls. To investigate the children's production of clitics, we used the elicitation task by Chondrogianni et al. (under review). This a picture-based elicitation task following Schaeffer's (2000) design. In this task, children were shown a picture with two characters on a computer screen and were told a story about the picture. Subsequently they were asked what character A did to character B, as in (16). This should elicit a clitic pronoun, as in (17).

(16) Experimenter: Ti kani o likos sti gata?

what does the wolf to-the cat

'What does the wolf do to the cat?'

(17) Target response: Ti filai

her.cl kisses

'He kisses her.'

All verbs in this task were actional transitive verbs (kiss, kick, hug, bite, pinch), and all arguments of the verbs were animals (bear, cat, deer, elephant, goat, lion, monkey, rabbit, sheep, wolf). The task consisted of 10 items. Of the 10 clitics, 4 were expected to be masculine, 3 feminine, and 3 neuter. 


\subsubsection{Results}

To address the children's production of clitics, we calculated their percentage of use of clitics, clitic omission, and substitution errors in which the clitic was substituted with an NP (there were no errors that involved substitution with a strong pronoun in either group), as shown in Table 6 . Comparison between the two groups using a Mann-Whitney U-test showed that the production of clitics in the children with ASD was lower than in the TD children $(z=-1.996, p=0.046)$. Children with ASD showed 7.34\% omission of clitics, whereas there were no errors of omission in the TD children $(z=-2.385, p=0.017)$. The two groups did not differ in the rate of substitutions $(z=-0.537, p=0.592)$.

\subsubsection{Interpretation of the Results}

The task on the production of clitics was used in order to test the hypothesis that the ASD children's errors in the binding of clitics relate to difficulties with clitics and not with difficulties with binding. Clitic omission may indicate that the children have difficulties with the syntactic and pragmatic conditions under which clitics are licensed, which may affect their rate of use, and have consequences for their reference/binding as well. The results show that the two groups of children made some substitution errors using a full NP instead of a clitic. Children with ASD substituted more clitics with full DPs than TD controls, yet, the difference was not significant. However, in terms of clitic omissions, the TD children did not omit any clitics in their production, whereas the children with ASD showed errors of omission. This finding is in line with the results of the comprehension task, supporting the hypothesis that errors in the binding of clitics could relate to the children's difficulties with licensing, and, consequently, production, of clitics.

\subsection{Follow-Up Study 2: Case Marking}

The second follow-up study was conducted in order to investigate whether the ASD children's lower performance on binding of clitics was due to difficulties with case marking with the consequences laid out in section 4.2.2.

TABLE 6

Participants' Accuracy on the Production of Clitics, and Errors of Omission and Substitution (\%)

\begin{tabular}{lccr}
\hline Group & Clitics & Omissions & Substitutions \\
\hline ASD children & & & 5.27 \\
$\quad$ Mean & 87.39 & 7.34 & 13.32 \\
SD & 20.73 & 11.62 & $0-50$ \\
Range & $20-100$ & $0-30$ & 2.26 \\
TD children & & & 6.67 \\
Mean & 97.74 & 0 & $0-25$ \\
SD & 6.67 & 0 & \\
Range & $75-100$ & 0 & \\
\hline
\end{tabular}




\subsubsection{Methodology}

Fifteen out of the 16 ASD children of Follow-up Study 1 study participated in the Follow-up Study 2. This was because one of the children in Follow-up Study 1 did not complete the session. Furthermore, three more children were not able to perform the task. As a result, the study on case of clitics includes only 12 of the children with ASD from the initial study along with their 12 age-matched TD controls.

A judgment task based on the task by Zachou \& Guasti (2010) was used to investigate the children's ability to detect case-marking errors of definite determiners, which are homophonous to the accusative object clitics (see also Zachou 2013). The task consisted of 24 experimental and 8 filler sentences. All experimental sentences contained an ungrammaticality in terms of case and included four error types (6 sentences per error type): (1) a masculine subject with an accusative determiner, as in (18a); (2) a masculine object with a nominative determiner, as in (19a); (3) a feminine subject with an accusative determiner, as in (20a); and (4) a feminine object with a nominative determiner, as in (21a). The grammatical counterparts of (18a)-(21a) are presented in (18b)-(21b).

(18) a. Ton likos xeretai ton kokora. (error: masc-subject, accusative case) the.acc wolf.nom greets the.acc rooster.acc/gen

'The wolf greets the rooster.'

b. O likos xeretai ton kokora. (grammatical) the.nom wolf.nom greets the.acc rooster.acc/gen

(19) a. O kokoras kitazi o liko. (error: masc-object, nominative case) the.nom rooster.nom looks at the.nom wolf.acc 'the rooster looks at the wolf.'

b. O kokoras kitazi to liko. (grammatical) the.nom rooster.nom looks at the.acc wolf.acc

(20) a. Tin kota akolouthi ti xelona. (error: fem-subject, accusative case) the.acc chicken.nom/acc follows the.acc turtle.nom/acc 'The chicken follows the turtle'

b. I kota akolouthi ti xelona. (grammatical) the.nom chicken.nom/acc follows the.acc turtle.nom/acc

(21) a. I xelona xeretai i kota. (error: fem-object, nominative case) the.nom turtle.nom/acc greets the.nom chicken.nom/acc 'The turtle greets the chicken.'

b. I xelona xeretai tin kota. (grammatical) the.nom turtle.nom/acc greets the.acc chicken.nom/acc

Feminine nominative and accusative nouns (but neither determiners nor clitics) are syncretic in Greek; hence, the ungrammaticality of (20a) and (21a) becomes apparent only when participants encounter the second NP of the sentences-see (20b) and (21b) for the grammatical counterparts of these sentences. In masculine nouns there is no syncretism. Therefore, there is also a concord error, that is, a mismatch in case between the article and the noun. When the ungrammaticality involves masculine nouns in the subject position (18a), a clear grammaticality effect is created at the beginning of the sentence, which is reinforced when participants encounter the second 
NP that has the same case marking as the first one. When the ungrammaticality is in the object position (19a), the grammaticality effect arises at the end of the sentence. This constellation of factors predicts better detection of ungrammaticality with masculine nouns because of the lack of syncretism.

If children with ASD make errors in binding of clitics because of difficulties with case, the prediction is that they may accept ungrammatical sentences with incorrect case marking. The most comparable contexts for the binding of clitics are contexts with a case error in the subject position, as in (18) and (20). This is because we hypothesized that children with ASD may have interpreted the target sentences with clitics, see (8), as a clitic left dislocation construction, see (15), repeated here. These two sentences are minimal pairs and differ only in the case of the subject NP.

(8) I mama tin pleni.

the.nom mom.nom/acc she.cl.acc wash.3s

'Mom is washing her.'

(15) Ti mama tin pro pleni.

the.acc mom.nom/acc she.acc.clitic (he/she) wash.3s

'(He/she) washes mom.'

All sentences were prerecorded and accompanied by an associated picture that created a context. Children had to judge whether sentences were "right" or "wrong," and they had to correct the wrong ones.

\subsubsection{Results}

To address the children's accuracy in detecting case ungrammaticality, we calculated their percentage of accurate rejection for each sentence type, as shown in Table 7.

Comparison among the four conditions using the Wilcoxon test showed that overall the two groups of children were better at rejecting ungrammaticality in the Masculine Subject condition (18a) than in the Feminine Subject condition (20a) $(z=-2.155, p=0.031)$; the difference between Feminine Subject (20a) and Feminine Object (21a) was approaching significance $(z=-1.876, p=0.061)$, an effect that is probably driven by the ASD children's performance.

TABLE 7

Participants' Accuracy in Rejecting Ungrammatical Case (\%)

\begin{tabular}{lcccc}
\hline Group & Masculine subject & Masculine object & Feminine subject & Feminine object \\
\hline ASD children & & & & \\
Mean & 91.67 & 95.83 & 73.61 & 94.44 \\
SD & 13.3 & 14.43 & 32.14 & 14.79 \\
Range & $66.7-100$ & $50-100$ & $16.7-100$ & $50-100$ \\
TD children & & & & 95.83 \\
Mean & 100 & 97.22 & 94.44 & 14.43 \\
SD & 0 & 9.62 & $50-100$ & $50-100$ \\
Range & 100 & $66.7-100$ & & \\
\hline
\end{tabular}


Comparison between the two groups using a Mann-Whitney U-test showed that the children with ASD had difficulties detecting the case ungrammaticality when it was in the subject position for masculine nouns $(z=-2.136, p=0.033)$, and this was also approaching significance for feminine nouns $(z=-1.859, p=0.063) .{ }^{10}$ There was no significant difference between the groups when the ungrammaticality was in the object position.

\subsubsection{Interpretation of Results}

This follow-up study investigated whether the children with ASD had difficulties with case marking, which could potentially lead to lower performance on binding of clitics for the reasons we explained. Our results did not reveal across-the-board difficulties with case. Difficulties in detecting case ungrammaticality were restricted to case errors in the subject position, mostly with feminine nouns, and, to a smaller extent, with masculine nouns. This pattern can be explained by the nature of the NPs used in the task. In feminine nouns, as a result of case syncretism of the noun, there is concord between the article and the noun in ungrammatical sentences, whereas there is a concord violation in masculine nouns. As a result of this, we have two ungrammaticalities in masculine nouns, one within the NP (concord) and the other with the syntactic function of the NP (e.g., accusative determiner used with the subject). Therefore, the better performance with masculine nouns presumably indicates the children's ability to detect concord violations within the NP in addition.

The lower performance of both groups on the Feminine Subject (20a) compared to the Feminine Object (21a) condition can be explained if we assume that children assign thematic roles incrementally as they listen to the sentences, and, in this process, they are guided by the case of the NP. In the Feminine Subject condition, they encounter first an NP in the accusative case, and as a result, they assign the patient role to the first NP, expecting nominative case for the second NP to assign the agent role. However, the second NP is also in the accusative case, so they have to reanalyze the thematic role of the first NP. In the Feminine Object condition, on the other hand, children encounter first a nominative NP and, as a result, they assign the thematic role of the agent to it, expecting accusative case for the second NP in order to assign the patient thematic role. This time they get another nominative marked NP, which is clearly ungrammatical, but they don't have to reanalyze the thematic role of the first NP. Since reanalysis is costly, it may be that this has caused lower accuracy in the first condition, rather than difficulties in detecting case errors.

To conclude, since children with ASD did not have across-the-board difficulties in detecting case errors, but only difficulties on specific conditions, we believe it is unlikely that the errors in binding of clitics are caused by case difficulties. Instead, since errors in detecting case ungrammaticality were limited to the subject position, and, moreover, to nouns that are ambiguous between nominative and accusative, they are more likely to follow from difficulties in reanalyzing the thematic role of the first NP in the sentence when they encounter the second one.

\footnotetext{
${ }^{10}$ The weaker statistical difference between children with ASD and TD children on feminine subjects as compared to masculine subjects is likely to be due to the large range on responses in feminine subjects for both groups and the ceiling effect on masculine subjects for the TD children.
} 


\section{GENERAL DISCUSSION}

This section summarizes the findings of all studies we have conducted, concluding the discussion on the comprehension of pronouns after the follow-up experiments, and presenting what we believe is its contribution in the domain of nonactive morphology for both ASD and typical language development.

\subsection{Pronouns}

In this subsection, besides concluding our discussion on the comprehension of pronouns by children with ASD, we will comment on the unexpected finding concerning binding of strong pronouns by the adult control group.

\subsubsection{Pronouns in $A S D$}

Starting with reflexive pronouns, we found that the ASD children of our study performed almost at ceiling, unlike the children in the study of Perovic, Modyanova \& Wexler (2013). As a result, we feel confident in suggesting that no problems with the reference of reflexive pronouns are to be encountered among high-functioning children with ASD in Greek. However, given that the study of Perovic, Modyanova \& Wexler did not include high-functioning children, and that the three low-functioning Greek-speaking children with ASD had serious problems with reflexive pronouns, we believe that binding of reflexive pronouns is a domain of grammar that deserves further investigation among low-functioning children with ASD not only in Greek, but also cross-linguistically.

Proceeding to clitic pronouns, an area that is usually unproblematic for typical development, we believe it is rather safe to conclude that it constitutes a domain of grammar that is affected in autism, perhaps not only in Greek. Such a belief is strengthened by the fact that the ASD children of our study were high functioning, with normal verbal and nonverbal abilities, and comparable to typically developing children in a number of baseline tasks (apart from pragmatics). Furthermore, the children with ASD were significantly different from the TD controls not only on the comprehension/binding of clitics, but also on their production. It is difficult to pinpoint with certainty what is responsible for these limitations. However, based on the elicitation task in particular, we believe that even high-functioning children with ASD have difficulties with the licensing of clitics, which, in turn, affect their ability to pick up the right referent of a pronominal clitic in binding tasks. It is well known that clitics are licensed by specific syntactic and semantic/pragmatic factors and have distinctive prosodic properties (see Mavrogiorgos 2010 for a recent thorough review). Given that the ASD children of our study performed lower than their TD controls on the pragmatics baseline task, the most reasonable suggestion to make is that they fall behind in the pragmatic conditions that call for the presence of a clitic, rather than of the corresponding DP. This said, we should call attention to the fact that a baseline pragmatics task, such as the one we administered, does not exactly tell us which aspect(s) of the licensing requirements of clitics may be affected, therefore, further inquiry toward this direction is required. For the very same reasons, we should not exclude research into whether children with ASD are aware of the prosodic properties of clitics, and whether (and how) these may affect their comprehension and production of these items. 
Nevertheless, regardless of the precise source behind Greek-speaking ASD children's difficulties with clitic pronouns, an area of grammar that has not been investigated among populations with ASD so far, it is reasonable to expect populations with autism to show difficulties with clitics, most possibly in a similar manner, crosslinguistically.

Finally, performance of high-functioning ASD children on binding of strong pronouns seems to be on a par with their typically developing controls at rates that agree with previous findings on Greek (see Varlokosta 2000). On the other hand, our findings from adult controls on this condition, to be discussed next, suggest that performance in this particular domain of grammar may never reach ceiling, but this by no means reflects problems with (properties of) pronouns or their binding.

\subsubsection{Strong Pronouns in Adult Language}

As reported already, a group of adult controls, students from the Engineering Departments of the Technological Educational Institute of Patras also completed the experimental task on binding of pronouns and nonactive morphology. The students' performance was at ceiling in all conditions, with the exception of a particularly low performance, by adult standards, on strong pronouns $(88.3 \%)$. Their performance was lower than the performance of ASD and TD children, and definitely much lower than their ceiling performance on all other tasks.

It is important to note that all errors adults made involved selection of a reflexive interpretation. Furthermore, 10 out the 14 errors were committed on the first occurrence of a sentence with a strong pronoun. At the end of the task we asked the participants to explain their choice of picture in this particular condition. The majority of them responded that, after answering the first sentence that contained a strong pronoun, they realized that something was wrong with interpreting the pronoun the way they did and revised their choice accordingly when the subsequent sentence of the same type appeared. Trying to understand what exactly they thought was wrong with the sentence, we asked them more specifically how they misinterpreted the pronouns afton/aftin ' him/her' in the instances they erred. In particular, we asked them whether:

(a) they mistook strong pronouns for the phonetically close reflexives, i.e., eafton 'himself/herself';

(b) they took strong pronouns to be the first part of the intensified logophor afton ton idio/afti tin idia 'him himself' /'her herself.'

Participants found it difficult to choose between these two possibilities, and we did not insist that they choose one. Given the options in (a) and (b), we believe that adult performance was affected by knowledge that strong pronouns are not felicitous as objects in a language with pronominal object clitics (with the exception of a strong deictic context, which was not the case in our task). Hence, when adults encounter a strong pronoun in this context, they tend to think that something else is actually said—and this "something else" always results in a reflexive interpretation precisely because the two options above are available. As the test continues, however, they realize that there is no other interpretation and revise their responses accordingly. Children may not have this particular knowledge established yet, namely, they may not know that strong pronouns in object position are felicitous only in deictic contexts; hence, they have no reason to look for alternative strategies. 


\subsection{Nonactive Morphology}

The results from the three conditions that investigated comprehension of verbs with nonactive morphology show that both groups of children have difficulties with some of the conditions, but children with ASD do not perform differently from TD controls. This indicates that nonactive morphology is not a vulnerable domain of grammar for children with ASD, or, at least for high-functioning Greek-speaking children with ASD. It should be reminded here that nonactive morphology is associated with a number of interpretations in Greek (see section 1.3). Of them, we singled out the reflexive and the passive. The latter constitutes a domain of grammar of much interest for typical language acquisition, and we believe that the findings from the TD children we studied contribute with new arguments to the ongoing discussion surrounding this domain. In what follows we discuss each of the conditions separately.

\subsubsection{Passive Verbs (with Passive Interpretation)}

As mentioned in section 1.3, passive sentences are considered to develop late in children's grammar, with empirical support from a number of languages in addition to English (Verrips 1996, among others). As for Greek, two previous studies using picture-selection tasks, Terzi \& Wexler (2002) and Driva \& Terzi (2008), showed that even up to the age of 6, Greek-speaking children do not attain ceiling performance on the comprehension of passive sentences. Zombolou et al. (2010) arrive at similar conclusions indirectly, namely, via studying children's production of anticausatives, which are structures that are widely held to be structurally similar to passives. On the other hand Tsimpli (2006) claims that Greek-speaking children have early knowledge of passives. As noted in previous sections, this claim has been based on a preferential judgment task with verbs that are ambiguous between a passive and a reflexive reading. In particular, 5- to 6-year-old children, the age group that is comparable to ours, gave a passive interpretation at the rate of $20 \%$, even on verbs that adults consider exclusively as reflexives. It seems to us, however, that one cannot tell with certainty from this finding how well children would do on sentences that can only have a passive reading, and how much such results would indeed differ from the ones we obtained. Recall that our tasks did not include preferential readings, hence, only one out of the three pictures shown to children corresponded to each sentence of the task. Moreover, our passive condition contained verbs that are considered passives on the basis of their incompatibility with the prepositional phrase "by herself/himself," see (6). ${ }^{11}$

One may be tempted to say that the results obtained on TD children's passives in Condition 4 of the current work replicate previous findings on the (late) acquisition of Greek passives. This is not entirely accurate, however, as the study of Terzi \& Wexler (2002) gave extremely low performance on verbal passives with the by-phrase, namely, around chance; nevertheless, it studied children who were much younger. On the other hand, the study of Driva \& Terzi (2008),

\footnotetext{
${ }^{11} \mathrm{~A}$ reviewer commented that the verbs we tested in this condition do not have only a passive interpretation, hence, they cannot be considered as passives, because most of them make perfect reciprocals if used in the plural. This is indeed true, however, we tested them in the singular, where no such ambiguity arises. It would admittedly be extremely interesting to investigate these verbs in the plural as passives, as well as reciprocals, on a par with Conditions 4 and 6 of the current experiment and compare the results. Obviously, such a task could not be undertaken within the confines set by the initial aims of this work.
} 
which investigated older children and used the same verbs as the ones in Terzi \& Wexler (2002), but with three rather than two pictures to chose from, gave considerably better results; children of mean age 6;0 gave $83 \%$ correct performance on passives without the by-phrase and $85 \%$ on passives with the by-phrase. The current study, which investigated children of mean age slightly higher than the children in Driva \& Terzi (2008), gave much lower results, namely, only $70 \%$ correct responses, a finding that cannot go unnoticed.

In order to address this unexpected difference, we looked closer at the items in our task for possible outliers and found that children of both groups performed considerably lower on the items that include the verbs klotsao 'kick' and filao 'kiss' (TD: kiss $=35 \%$, kick $=52 \%$; ASD: kick $=26 \%$, kiss $=48 \%$, correct performance). We are unable to tell what may have caused the poor performance on these two verbs, although we tend to think that the picture for 'kiss' may have been confusing. ${ }^{12}$ Nevertheless, in investigating whether or not the lower scores in our study are caused by the low scores in those two items, we (re)calculated the results without them and found that the mean accuracy in this condition is $85 \%$ for the TD children and $82 \%$ for the children with ASD. Moreover, (a) TD and ASD children still did not differ from each other $(F(1$, $38)=0.41, p>0.1$ ), and (b) their performance on the four remaining verbs was still significantly lower than on the other two conditions $(F(2,76)=15.13, p=0.001$; passives vs. reflexives with passive interpretation: $p=0.001$; passives vs. reflexives with reflexive interpretation: $p<0.001$ ). With these refinements in mind, we will now discuss the reasons that may be responsible for the low performance on passives.

Late acquisition of passives has been attributed to delay of maturation of A-chains by Borer \& Wexler (1987), recast by Wexler (2004) as the Universal Phase Requirement (UPR). According to the UPR, children cannot raise the object DP to spec, $\mathrm{T}$ in passives because they cannot raise it to spec, $\mathrm{v}$ first, since they perceive passive $\mathrm{v}$ to be a phase, but without features relevant for the object. A more recent proposal along similar lines is offered by Hyams, Ntelitheos \& Manorohanta (2006); according to it: Children cannot form A-chains that derive a misalignment of thematic and grammatical hierarchies; that is, an external argument, if there is one, maps onto the subject (Canonical Alignment Hypothesis- $\mathrm{CAH}$ ). Therefore, passives are not mastered early because what is mapped onto the subject position of the sentence is not the agent. Unaccusatives, on the other hand, may be less problematic because, although their subject is not an agent, CAH is not violated since they do not have an agent. Hyams, Ntelitheos \& Manorohanta admit that it is not entirely clear why this is so, and conjecture that it is related to a more general property of the language faculty.

However, low performance on passives has also been attributed to low occurrence of passives in the input children receive, especially in a language such as Greek, which employs alternative strategies, such as Clitic Left Dislocation or Clitic Doubling, to give prominence to the element that is the subject of a passive sentence. The position of Tsimpli (2006) and Fotiadou \& Tsimpli (2010) on a possible late mastery of Greek passives is along these lines. ${ }^{13}$

\footnotetext{
${ }^{12} \mathrm{~A}$ reviewer comments that not all native speakers accept some of the passive sentences employed in the task, in particular, those containing the verbs 'pinch,' 'feed,' and 'kiss.' This observation may be able to explain low performance of children on 'kiss,' but not on 'kick.' Moreover, performance on the first two verbs that do not make felicitous passives according to the reviewer was not particularly low.

${ }^{13}$ Views that attribute early appearance of passives to their high occurrence in the input children receive are held by Demuth (1989), and subsequent work, for Sesotho. However, a recent study of Sesotho passives found that Sesothospeaking children in fact perform no better than English-speaking children, although the frequency of passives in Sesotho is much higher than in English (Crawford 2012).
} 


\subsubsection{Reflexive Verbs (with Reflexive Interpretation)}

The results on reflexive verbs with reflexive interpretation contrast the results on verbs with nonactive morphology and passive interpretation, or else what we have considered passive verbs in the previous condition. Both typically developing and ASD children did extremely well on this condition, answering correctly at $99.2 \%$ and $96.7 \%$ of the time respectively.

It could be suggested that the different pattern on passives versus reflexives is due to frequency differences in the input between the two types of verbs. Reflexive verbs appear early in children's language input, as they are used in daily activities (body care/grooming verbs, such as comb, wash, etc., for instance) and are very frequent in child-directed speech (see also the following subsection).

On the other hand, the different behavior of the TD children on these two types of verbs that share the same (nonactive) morphology could be attributed to the fact that the latter involve a different, and less complex syntactic structure in the relevant sense, despite morphological resemblance. It has actually been argued on the basis of a number of diagnostics that the subjects of reflexive verbs are external arguments, unlike the subjects of unaccusatives, that is, they are not derived subjects, see Reinhart \& Siloni $(2004,2005)$ for a number of languages, Papangeli (2004) for Greek in particular, and Labelle (2008) for French. This view is also shared by Tsimpli (2006) ${ }^{14}$ Hence, the subject of a reflexive verb either receives both agent and theme/patient thetaroles via the operation Reinhart \& Siloni (2005) call (thematic role) bundling or determines the recipient of the internal theta-role by virtue of being introduced by this particular morphology, if one extended the proposals of Labelle (2008) for French se.

Therefore, regardless of the stand one adopts, the almost-at-ceiling performance of TD children on reflexive verbs does not come as a surprise. We believe, however, that high frequency in the input cannot be the whole story for the successful acquisition of reflexive verbs by Greek-speaking children, as we will be demonstrate in the following section.

\subsubsection{Reflexive Verbs with Passive Interpretation: Why Frequency Is Not Important}

Reflexive verbs can be ambiguous between a reflexive and a passive reading, given appropriate pragmatic conditions, as pointed out in section 1.3.2. While Condition 5 tested these verbs on the former reading, Condition 6 is testing the very same verbs on the latter. This is done by providing contexts in which only a passive reading is felicitous among the sets of three pictures shown to the participants.

Results showed that TD children did much better on this type of passives than on those of Condition 4 and that the difference was significant even after we removed the two verbs on which they performed poorly in Condition 4. The question that arises, therefore, is why and to what this difference is due. Before we attempt to offer an answer, we will explain what we think it is not due to.

We believe that the fact that TD children did extremely well on the passive reading of reflexive verbs demonstrates that the low(er) performance of the same children on passives in Condition 4 cannot be due to the infrequent presence of passives in the language input, as is often held. This

\footnotetext{
${ }^{14}$ Such views of reflexives contrast with views such as of Embick (2004), who considers reflexives like unaccusatives in the sense that they both involve derived subjects.
} 
is because reflexive verbs with passive interpretation are extremely rare, yet, children did fine on them. We have two pieces of evidence for the infrequent presence of these verbs in the input. First, we had an informal run of the test with 20 of our students, to whom we showed the experiment on the board using PowerPoint and asked them to mark the correct choice on their own on a piece of paper. About half of them did not provide an answer on this particular condition (but the ones who did, provided the target answer). Second, in a survey of child-directed speech from the Stephany corpus, Fotiadou \& Tsimpli (2010) found that the great majority of verbs with nonactive morphology were indeed reflexives $(183 / 244)$, with the remaining 61 being passives and reciprocals. What is most crucial is that reflexive verbs were only used with a reflexive interpretation in the corpus, i.e., they were never used as passives. It should be noted that this survey looked at childdirected speech to children up to 2;09 years old, but there are no reasons to believe that things would be much different in speech that addresses older children. Yet, these were verbs on which the TD children of our study did almost at ceiling. If frequency in the input was of crucial importance for the acquisition of passives, we would expect TD children to have a better performance on passives than on reflexive verbs with passive interpretation, contrary to what we found.

Why is it then that TD children do better on passives that employ reflexive verbs? We believe this is so because they are exposed to reflexive verbs from early on and know their structure. They know that their subject is a patient, and this does not create problems for alignment, especially if it is not a derived subject, as held by some of the various accounts mentioned in the previous section. On the other hand, the only way they would know that the subject of a passive sentence in Condition 4 is a theme/patient is if they knew that the subject of the sentence is a derived one; but then problems either with A-chains or with canonical alignment arise. ${ }^{15}$

TD children's highly correct performance in this condition leads us to believe that they interpret the subject of the sentence as the patient; something they know by knowing reflexive verbs. However, how about the fact that the subject is also an agent? We are led to believe that children do not necessarily interpret the agents of the action, i.e., the persons who perform the action in the target pictures of this condition, (and other conditions, to be made precise) as agents. Instead, they may consider the agents as sources, or even ignore them, despite the fact that they are present in the pictures. There is in fact evidence pointing to this direction: first, the findings of Zombolou et al. (2010) show that the presence of an agent did not make a difference for the (admittedly, younger) children's production of anticausative verbs with nonactive morphology in Greek. Moreover, Driva \& Terzi (2008), who studied children of similar age as the children of the current study on passives with and without a by-phrase, found that the presence of the by-phrase did not make a difference for the children's performance. As to why children do not also ignore agents of active verbs; this may be because the subject of the sentence would then be left without a theta-role.

To conclude, it is important to note that children with ASD seem to have followed similar steps in interpreting nonactive sentences, since they have similar levels of accuracy as TD children. Note also that the adult controls who participated in the experiment performed at ceiling on all nonactive conditions. If better pragmatic abilities assist adults in their performance on noncanonical sentences, and, in particular, on passives, as suggested by Hyams, Ntelitheos \& Manorohanta (2006, footnote 18), while children adhere more strictly to "shape preservation,"

\footnotetext{
${ }^{15} \mathrm{~A}$ reviewer comments that passives are often better in the past tense in Greek, referring to observations due to Zombolou (2004). This may be true, but the passive condition that employed reflexive verbs, i.e., Condition 6, also used verbs in nonpast, yet, performance was much higher than on the passives of Condition 4.
} 
one can conclude that children with ASD did not differ importantly from TD children in their use of pragmatics for interpreting passive sentences, despite their different pragmatic skills as assessed by the baseline task.

\section{CONCLUSIONS}

The central aim of this research was to reveal particular characteristics of the grammar of individuals with ASD. We studied high-functioning Greek-speaking children with autism and Greek-speaking TD children in order to evaluate whether earlier findings based on Englishspeaking populations with ASD, and, in particular, low performance on binding of reflexive pronouns, can be considered to hold cross-linguistically in autism. The results showed no common pattern between the two languages. Nevertheless, there is some evidence that binding of reflexive pronouns lags behind among low-functioning children of the autism spectrum even in Greek, but this finding remains to be further investigated.

However, we believe we have discovered another domain, which has no counterpart in English, although it has in many other languages, and is affected even among high-functioning children with ASD; this is the domain of clitic pronouns, in which Greek-speaking children were found to perform lower than the TD control group. We demonstrated that there are reasons to believe that the problems children with ASD have on both the comprehension/binding and the production of clitics stem from insufficient familiarity with the conditions that license the presence of a clitic. Future research targeting pragmatic and prosodic aspects of clitics and assessing pragmatics and prosody independently of them can provide firm conclusions about the nature of the difficulties and decide whether pragmatic aspects are indeed at stake, as indicated by the lower performance of ASD children on a pragmatics baseline task they completed, or whether prosody is also crucially involved. Moreover, research on autism in other languages with clitics will be able to evaluate how widespread this behavior is, as well as contribute to discovering the causes of such a potentially cross-linguistic weakness.

As for nonactive morphology, ASD children did not appear to differ significantly from the typically developing children in our study, and this includes passives, a difficult domain of grammar for typical acquisition of Greek. If we accept that adults make use of pragmatics in order to interpret passives, judging from the similar performance of both groups of children on passive sentences, we are led to conclude that they employed pragmatics to the same extent in this task. Children of both groups were less accurate on passive than reflexive verbs, even when the latter were used with passive interpretation. We argued that the different performance between nonactive conditions cannot be attributed to frequency effects in the input that children receiveas they seem to receive less input for the condition on which they perform better. Different performance may, however, be related to the linguistic representation associated with passive and reflexive verbs.

\section{ACKNOWLEDGMENTS}

We would like to thank the clinics in Athens, Messolongi, and Pyrgos for allowing us to recruit the children with ASD; public schools 19 and 60, and public kindergarten 42 in Patras, for allowing us to recruit TD children; and the children and their parents for taking part in the 
study. Earlier parts of this work were presented at the 7th European Group for Child Language Disorders Conference (Eucldis) (Chalkidiki, May 2011), at the University of Reading (July 2011), the 3rd Conference for Autism Spectrum Impairments (Messolongi, October 2011), the 36th Boston University Conference on Language Development (November 2011), the Workshop on Pronoun Binding and Nonactive Morphology in Greek (Technological Educational Institute of Patras, November 2011), the Linguistics Meeting at the University of Ioannina (May 2012), and the Patras Goes Psycho Meeting at the University of Patras (June 2012). We would like to thank the audiences of these events for their comments and suggestions. Thanks also to Dimitra Bafa for collecting the data and to Sofi Miliopoulou for drawing the pictures. Last but not least, we would like to thank three Language Acquisition reviewers for their insightful comments. Errors or omissions are our own responsibility, of course.

\section{FUNDING}

Support for the research reported here was provided by a 2011 Latsis Foundation grant (Mapping out the Linguistic Profile of Greek-Speaking Individuals with Autism Spectrum Disorders), which is hereby gratefully acknowledged.

\section{REFERENCES}

Alexiadou, Artemis \& Elena Anagnostopoulou. 2004. Voice morphology and the causative-inchoative alternation: Evidence for a non-unified structural analysis of unaccusatives. In Artemis Alexiadou, Elena Anagnostopoulou \& Martin Everaert (eds.), The unaccusativity puzzle: Explorations in the syntax-lexicon interface, 114-136. Oxford: Oxford University Press.

Alexiadou, Artemis, Elena Anagnostopoulou \& Florian Schäfer. 2006. The properties of anticausatives crosslinguistically. In Mara Frascarelli (ed.), Phases of interpretation, 187-211. Berlin/New York: Mouton de Gruyter.

American Psychiatric Association. 1994. DSM-IV sourcebook, Vol. I. Washington, DC: American Psychiatric Association.

Anagnostopoulou, Elena \& Martin Everaert. 1999. Towards a more complete typology of anaphoric expressions. Linguistic Inquiry 30. 97-118.

Avrutin, Sergey \& Kenneth Wexler. 1992. Development of principle B in Russian: Coindexation at LF and coreference. Language Acquisition 2. 259-306.

Baauw, Sergio, María A. Escobar \& William Philip. 1997. A delay of principle B effect in Spanish speaking children: The role of lexical feature acquisition. In Antonella Sorace, Caroline Heycock \& Richard Shillcock (eds.), Proceedings of the GALA 97 Conference on Language Acquisition, 16-21. Edinburgh: HCRC.

Bartolucci, Giampiero \& Robert J. Albers. 1974. Deictic categories in the language of autistic children. Journal of Autism and Developmental Disorders 4. 131-141.

Bartolucci, Giampiero, Sandra J. Pierce \& David Streiner. 1980. Cross-sectional studies of grammatical morphemes in autistic and mentally retarded children. Journal of Autism and Developmental Disorders 10. 39-50.

Borer, Hagit \& Kenneth Wexler. 1987. The maturation of syntax. In Thomas Roeper \& Edwin Williams (eds.), Parameter setting, 123-172. Dordrecht, The Netherlands: Reidel.

Cardinaletti, Anna \& Michal Starke. 1999. The typology of structural deficiency: A case study of the three classes of pronouns. In Henk van Riemsdijk (ed.), Clitics in the languages of Europe, 145-233. Berlin: Mouton de Gruyter

Chien, Yu-Chin \& Kenneth Wexler. 1990. Children's knowledge of locality conditions in binding as evidence for the modularity of syntax and pragmatics. Language Acquisition 1. 225-295.

Chondrogianni, Vasiliki, Theodoros Marinis \& Susan Edwards. 2010. On-line processing of articles and pronouns by Greek successive bilingual children: Similar or different from children with SLI? In Katie Franich, Kate M. Iserman \& Lauren L. Keil (eds.), Proceedings of the 34th Annual Boston University Conference on Language Development [BUCLD 34], 78-89. Somerville, MA: Cascadilla Press. 
Chondrogianni, Vasiliki, Theodoros Marinis, Susan Edwards \& Elma Blom. under review. Production and on-line comprehension of definite articles and clitic pronouns by Greek sequential bilingual children and monolingual children with SLI.

Colle, Livia, Simon Baron-Cohen, Sally Wheelwright \& Heather K. J. van der Lely. 2008. Narrative discourse in adults with high-functioning autism or Asperger Syndrome. Journal of Autism and Developmental Disorders 38. 28 -40.

Conroy, Anastasia, Eri Takahashi, Jeffrey Lidz \& Colin Phillips. 2009. Equal treatment for all antecedents: How children succeed with principle B. Linguistic Inquiry 40. 446-486.

Crawford, Jean L. 2012. Developmental perspectives on the acquisition of the passive. Storrs, CT: University of Connecticut dissertation.

Demuth, Katherine. 1989. Maturation and the acquisition of the Sesotho passive. Language 65. 56-80.

Driva, Evangelia \& Arhonto Terzi. 2008. Children's passives and the theory of grammar. In Anna Gavarró \& Maria João Freitas (eds.), Generative approaches to language acquisition 2007, 189-200. Cambridge: Cambridge Scholar Publishers.

Dunn, Lloyd M. \& Douglas M. Dunn. 1997. Peabody Picture Vocabulary Test. 3rd edn. Circle Pines, MN: American Guidance Service.

Eigsti, Inge-Marie \& Loisa Bennetto. 2009. Grammaticality judgments in autism: Deviance or delay? Journal of Child Language 36. 999-1021.

Embick, David. 2004. Uncaccusative syntax and verbal alternations. In Artemis Alexiadou, Elena Anagnostopoulou \& Martin Everaert (eds.), The unaccusativity puzzle: Explorations in the syntax-lexicon interface, 137-158. Oxford: Oxford University Press.

Fotiadou, Georgia \& Ianthi Maria Tsimpli 2010. The acquisition of transitivity alternations in Greek: Does frequency count? Lingua 120. 2605-2626.

Hobson, Peter R., Anthony Lee \& Jessika A. Hobson. 2010. Personal pronouns and communicative engagement in autism. Journal of Autism and Developmental Disorders 40. 653-664.

Hyams, Nina, Dimitrios Ntelitheos \& Cecile Manorohanta. 2006. Acquisition of the Malagasy voicing system: Implications for the adult grammar. Natural Language and Linguistic Theory 24. 1049-1092.

Iatridou, Sabine. 1988. Clitics, anaphors, and a problem of coindexation. Linguistic Inquiry 19. 698-703.

Kjelgaard, Margaret M. \& Helen Tager-Flusberg. 2001. An investigation of language impairment and autism: Implications for genetic subgroups. Language and Cognitive Processes 16. 287-308.

Labelle, Marie. 2008. The French reflexive and reciprocal se. Natural Language and Linguistic Theory 26. 833-876.

Lely, Heather K. J. van der \& Linda Stollwerck. 1997. Binding theory and grammatical specific language impairment in children. Cognition 62. 245-290.

Leonard, Laurence. 1998. Children with specific language impairment. Cambridge, MA: MIT Press.

Lord, Catherine, Susan Risi, Linda Lambrecht, Edwin H. Cook Jr., Bennett L. Leventhal, Pamela C. DiLavore, Andrew Pickles \& Michael Rutter. 2000. The Autism Diagnostic Observation Schedule-Generic: A standard measure of social and communication deficits associated with the spectrum of autism. Journal of Autism and Developmental Disorders 30. 205-223.

Manika, Sophia, Spyridoula Varlokosta \& Ken Wexler. 2011. The lack of omission of clitics in Greek children with SLI: An experimental study. In Nick Danis, Kate Mesh \& Hyunsuk Sung (eds.), Proceedings of the 35th Annual Boston University Conference on Language Development [BUCLD 35], 427-439. Somerville, MA: Cascadilla Press.

Mastropavlou, Maria. 2006. The role of phonological salience and feature interpretability in the grammar of typically developing and language impaired children. Thessaloniki, Greece: University of Thessaloniki dissertation.

Mavrogiorgos, Marios. 2010. Clitics in Greek: A minimalist account of proclisis and enclisis. Amsterdam: John Benjamins.

McCann, Joanne \& Sue Peppé. 2003. Prosody and autistic spectrum disorders: A critical review. International Journal of Language and Communication Disorders 38. 325-350.

McKee, Cecile. 1992. A comparison of pronouns and anaphors in Italian and English acquisition. Language Acquisition 2. 21-54.

Novogrodsky, Rama \& Naama Friedmann. 2006. The production of relative clauses in SLI: A window to the nature of the impairment. Advances in Speech-Language Pathology 8. 364-375.

Novogrodsky, Rama \& Naama Friedmann. 2010. Not all dependencies are impaired in syntactic-SLI: Binding in children with a deficit in Wh-movement. In Katie Franich, Lauren L. Keil, \& Kate M. Iserman (eds.), Online Proceedings Supplement of the 34th Annual Boston University Conference on Language Development [BUCLD 34]. 
Papangeli, Dimitra. 2004. The morphosyntax of argument realization: Greek argument structure and the lexicon-syntax interface. Utrecht, The Netherlands: University of Utrecht dissertation.

Perovic, Alexandra, Nadya Modyanova \& Ken Wexler. 2013. Comprehension of reflexive and personal pronouns in children with autism: A syntactic or pragmatic deficit? Applied Psycholinguistics 34. 813-835.

Raven, John C. 1998. The coloured progressive matrices. Oxford: Oxford University Press.

Reinhart, Tanya \& Eric Reuland. 1993. Reflexivity. Linguistic Inquiry 24. 657-720.

Reinhart, Tanya \& Tal Siloni. 2004. Against the unaccusative analysis. In In Artemis Alexiadou, Elena Anagnostopoulou \& Martin Everaert (eds.), The unaccusativity puzzle: Explorations in the syntax-lexicon interface, 159-180. Oxford: Oxford University Press.

Reinhart, Tanya \& Tal Siloni. 2005. The lexicon-syntax parameter: Reflexivization and other arity operations. Linguistic Inquiry 36. 389-436.

Riches, Nick G., Tom Loucas, Gillian Baird, Tony Charman \& Emily Simonoff. 2010. Sentence repetition in adolescents with specific language impairments and autism: An investigation of complex syntax. International Journal of Language and Communication Disorders 45. 47-60.

Roberts, Jenny A., Mabel L. Rice \& Helen Tager-Flusberg. 2004. Tense marking in children with autism. Applied Psycholinguistics 25. 429-448.

Schaeffer, Jeannette C. 2000. The acquisition of direct object scrambling and clitic placement. Amsterdam/Philadelphia: John Benjamins.

Seymour, Harry N., Thomas W. Roeper, Jill de Villiers \& Peter de Villiers. 2005. Diagnostic Evaluation of Language Variation $\left(D E L V^{T M}\right)$-Norm Referenced. San Antonio, TX: Harcourt Assessment.

Smith, Nafsika. 2009. Morphosyntactic skills and phonological short-term memory in Greek preschool children with specific language impairment. Reading, UK: University of Reading dissertation.

Spathas, Giorgos. 2010. Focus in anaphora. Utrecht, The Netherlands: University of Utrecht dissertation.

Stavrakaki, Stavroula \& Heather van der Lely. 2010. Production and comprehension of pronouns by Greek children with specific language impairment. British Journal of Developmental Psychology 28. 189-216.

Stavrakaki, Stavroula \& Ianthi Maria Tsimpli. 2000. Diagnostic verbal IQ test for Greek preschool and school age children: Standardization, statistical analysis, psychometric properties. Proceedings of the 8th Symposium of the Panhellenic Association of Logopedists, 95-106. Athens: Ellinika Grammata.

Tager-Flusberg, Helen. 1999. A psychological approach to understanding the social and language impairments in autism. International Review of Psychiatry 11. 325-344.

Tager-Flusberg, Helen, Susan Calkins, Tina Nolin, Therese Baumberger, Marcia Anderson \& Ann Chadwick-Dias. 1990. A longitudinal study of language acquisition and Down Syndrome children. Journal of Autism and Developmental Disorders 20. 1-21.

Terzi, Arhonto, Theodoros Marinis, Kostantinos Francis \& Angeliki Kotsopoulou. 2012. Crosslinguistic differences in autistic children's comprehension of pronouns: English vs. Greek. In Alia K. Biller, Esther Y. Chung \& Amelia E. Kimball (eds.), Proceedings of the 36th Annual Boston University Conference on Language Development, [BUCLD 36], 607-619. Somerville, MA: Cascadilla Press.

Terzi, Arhonto \& Ken Wexler. 2002. A-chains and S-homophones in children's grammar: Evidence from Greek passives. In Masako Hirotani (ed.), Proceedings of the 32nd North Eastern Linguistic Society [NELS 32], 519-537. Amherst, MA: GLSA Publications.

Tsimpli, Ianthi Maria. 2006. The acquisition of voice and transitivity alternations in Greek as native and second language. In Sharon Unsworth, Teresa Parodi, Antonella Sorace \& Martha Young-Scholten (eds.), Paths of development in L1 and L2 acquisition: In honor of Bonnie D. Schwartz, 15-55. Amsterdam: John Benjamins.

Tsimpli, Ianthi Maria \& Stavroula Stavrakaki. 1999. The effects of a morphosyntactic deficit in the determiner system: The case of a Greek SLI child. Lingua 108. 31-85.

Varlokosta, Spyridoula. 2000. Lack of clitic pronoun distinctions in the acquisition of principle B in child Greek. In Cathrine S. Howell, Sarah A. Fish \& Thea Keith-Lucas (eds.), Proceedings of the 24th Boston University Conference on Language Development, [BUCLD 24], 738-748. Somerville, MA: Cascadilla Press.

Varlokosta, Spyridoula. 2002. (A)symmetries in the acquisition of principle B in typically-developing and specifically language impaired (SLI) children. In Inge Lasser (ed.), The process of language acquisition, 81-98. Berlin: Peter Lang Verlag Publishing.

Varlokosta, Spyridoula. 2008. The typology of pronouns and the acquisition of principle B. Talk given at the Athens Reading Group in Linguistics, December, Athens. 
Varlokosta, Spyridoula \& Michaela Nerantzini. 2012. Pronominal and anaphoric reference in Greek specific language impairment. In Zoe Gavriilidou, Angeliki Efthymiou, Evangelia Thomadaki \& Penelope Kambakis-Vougiouklis (eds.), Selected papers of the 10th International Conference of Greek Linguistics, 584-591. Komotini, Greece: Democritus University of Thrace.

Veripps, Maaike. 1996. Potatoes must peel: The acquisition of the Dutch passive. Amsterdam: University of Amsterdam dissertation.

Wexler, Kenneth. 2004. Theory of phasal development. MIT Working Papers in Linguistics 48. 159-209.

Wexler, Kenneth \& Yu-Chin Chien. 1985. The development of lexical anaphors and pronouns. Papers and Reports on Child Language Development 24. 138-149.

World Health Organization. 1993. The ICD-10 classification of mental and behavioral disorders: Diagnostic criteria for research. Geneva: WHO.

Zachou, Angeliki. 2013. Language production and comprehension in developmental dyslexia and specific language impairment: Evidence from Italian and Greek. Milan, Italy: University of Milan, Bicocca dissertation.

Zachou, Angeliki \& Maria Teresa Guasti. 2010. A series of tests for the investigation of language deficits in specific language impairment and developmental dyslexia in Italian and Greek (Greek Version). Ms. Università degli Studi di Milano-Bicocca.

Zombolou, Katerina. 2004. Verbal alternations in Greek: A semantic analysis. Reading, UK: University of Reading dissertation.

Zombolou, Katerina, Spyridoula Varlokosta, Artemis Alexiadou \& Elena Anagnostopoulou. 2010. Acquiring anticausatives vs. passives in Greek. In Katie Franich, Kate M. Iserman \& Lauren L. Keil (eds.), Proceedings of the 34th Annual Boston University Conference on Language Development [BUCLD 34], 515-524. Somerville, MA: Cascadilla Press.

\section{APPENDIX: COMPLETE LIST OF SENTENCES}

\section{Practice Sentences}

O papus luzete

I Keti tin pleni
'Grandpa is shampooing himself'

'Kate is washing her'

\section{Condition 1: Strong Pronouns}

I giagia xaidevi aftin

O papus luzi afton

I Maria pleni aftin

O babas skupizi afton

I mama dini aftin

O Kostas skepazi afton
'Grandma is caressing her'

'Grandpa is shampooing him'

'Mary is washing her'

'Dad is wiping him'

'Mom is dressing her'

'Kostas is covering him' 


\section{Condition 2: Clitics}

\author{
O papus ton skepazi \\ I Maria tin xaidevi \\ O Kostas ton skupizi \\ O thios ton dini \\ I nona tin luzi \\ I mama tin pleni
}

\author{
'Grandpa is covering him' \\ 'Mary is caressing her' \\ 'Kostas is wiping him' \\ 'The uncle is dressing him' \\ 'The godmother is shampooing her' \\ 'Mom is washing her'
}

\section{Condition 3: Reflexive Pronouns}

I Maria agaliazi ton eafto tis O Giorgos skepazi ton eafto tu O Kostas skupizi ton eafto tu I Maria zografizi ton eafto tis O Petros kitazi ton eafto tu I Keti xaidevi ton eafto tis

\section{Condition 4: Passive Verbs}

O Giorgos kinigiete

O thios klotsiete

O papus taizete

I mama filiete

I nona tsimbiete

I Maria sproxnete
'Mary is hugging herself' 'George is covering himself' 'Kostas is wiping himself' 'Mary is painting herself' 'Petros is looking at himself' 'Kate is caressing herself'

\section{Condition 5: Reflexive Verbs}

O Kostas plenete

I Maria luzete

I Eleni skupizete

O Petros skepazete

O Giorgos dinete

I Eleni xaidevete
'George is being chased'

'The uncle is being kicked'

'Grandpa is being fed'

'Mom is being kissed

'The godmother is being pinched'

'Mary is being pushed'

\section{Condition 6: Reflexive Verbs with Passive Interpretation}

I Keti skupizete

$\mathrm{O}$ thios dinete

O Giorgos skepazete

I giagia plenete

I Maria xaidevete

O Kostas luzete
'Kate is being wiped'

'The uncle is being dressed'

'George is being covered'

'Grandma is being washed'

'Mary is being caressed'

'Kostas is being shampooed' 